\title{
Pie plano adquirido del adulto por disfunción del tibial posterior. Opciones para el tratamiento quirúrgico
}

\author{
Acquired flat foot of the adult by posterior tibial dysfunction. Options for surgical treatment
Núñez-Samper M,* Llanos-Alcázar LF,‡ Viladot-Pericé R,§ Viladot-Voegeli A,§ Álvarez-Goenaga F,§

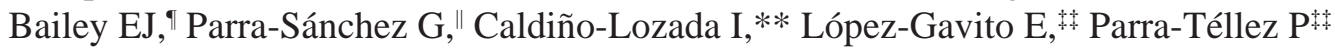

Hospital Virgen del Mar. Madrid, España.

RESUMEN. Presentamos la posible causa etiopatogénica de la disfunción del tibial posterior o pie plano doloroso del adulto y la relación causa-efecto que puede existir. También exponemos la clasificación de la lesión y las diferentes opciones para el tratamiento quirúrgico de la deformidad. Desde 1939, múltiples artículos han sido publicados, avalados por la clínica, así como por estudios experimentales, electromiográficos y biomecánicos; publicaciones consultadas y evaluadas para el desarrollo de esta revisión, según nuestro criterio: el primum movens de la disfunción del tibial posterior es ocasionado por un fallo del ligamento en hamaca o calcáneo navicular plantar (spring ligament), principal estabilizador pasivo del arco plantar interno. Este fallo supondría en el tiempo un aumento de trabajo del tendón tibial posterior, de por sí «insuficiente», que entraría en fatiga hasta llegar a la rotura parcial o total. Los trabajos publicados en relación con los procedimientos de partes blandas que actúan sobre el tendón tibial posterior en el estadio II no han tenido el resultado esperado en la historia natural de la deformidad. La artrodesis por el contrario, ha sido efectiva en otros estadios, pero está asociada a una pérdida de la dinámica del movimiento en el retropié y a un aumento de la presión en las articulaciones adyacentes.

Palabras clave: Disfunción del tibial posterior, ligamento en hamaca, pie plano doloroso del adulto.
ABSTRACT. We present the possible etiopatogenic causes of posterior tibial dysfunction or painful flat foot of the adult and the cause-and-effect relationship that may exist. We also expose the gradation of the lesion and the different therapeutic options for the surgical treatment of the deformity. Since 1939, multiple articles have been published, which have been endorsed by clinical, experimental, electromyographic and biomechanical studies; publications that have been consulted and evaluated for the development of this review. In our opinion: the dysfunction of the posterior tibial is caused in principle by a failure of the plantar navicular calcaneus ligament (spring ligament), the main passive stabilizer of the internal plantar arch. This failure would, in time, mean an increase in work of the posterior tibial tendon, in itself «insufficient», which would go into fatigue, until it reached a partial or total rupture. Published work on soft-part procedures acting on the posterior tibial tendon in stage II has not had the expected result in the natural history of deformity. Arthrodesis, on the other hand, has been effective in other stages, but is associated with a loss of movement dynamics in the back foot and increased pressure on adjacent joints.

Keywords: Tibialis posterior disfunction, spring ligament, acquired adult flat foot.

\footnotetext{
* Servicio de Cirugía Ortopédica, Hospital Virgen del Mar. Madrid, España. ORCID: 0000-0001/9398-0375.

¥ Servicio de Cirugía Ortopédica, Hospital 12 de Octubre. Madrid, España.

$\S$ Servicio de Cirugía Ortopédica, Hospital Tres Torres. Barcelona, España.

"Orthopaedic Surgery Service. Orthopaedics Midtown Hospital. Atlanta, Georgia, USA.

" Unidad de Pie y Tobillo del Hospital Gregorio Marañón. Madrid, España.

** Unidad de Pie y Tobillo del Hospital de Ortopedia de Cruz Roja. Yucatán, México.

\# División de Pie y Tobillo y DNM del Instituto Nacional de Rehabilitación. Ciudad de México.
}

Correspondencia:

Mariano Núñez-Samper, MD. PhD.

E-mail: mnusamp1@nunezsamper.com

Recibido: 31-03-2020. Aceptado: 05-01-2021.

Citar como: Núñez-Samper M, Llanos-Alcázar LF, Viladot-Pericé R, Viladot-Voegeli A, Álvarez-Goenaga F, Bailey EJ, et al. Pie plano adquirido del adulto por disfunción del tibial posterior. Opciones para el tratamiento quirúrgico. Acta Ortop Mex. 2021; 35(1): 92-117. https://dx.doi.org/10.35366/100938 


\section{Conceptos anatomofuncionales}

El pie plano progresivo adquirido del adulto es una deformidad tridimensional que afecta a múltiples articulaciones (subluxación dorsolateral periastragalina), ${ }^{1}$ incluyendo alteraciones en el plano sagital (con aplanamiento del arco medial), en el transverso (abducción del antepié) y en el coronal (valgo de retropié). Secundariamente pueden afectarse otras articulaciones de la columna medial tales como la astragaloescafoidea o la primera cuneometatarsiana. Clásicamente el pie plano se atribuye a una disfunción del tendón del músculo tibial posterior, ${ }^{2}$ que afecta preferentemente a mujeres premenopáusicas o postmenopáusicas.

El tendón tibial posterior transcurre por un surco fibroóseo independiente por detrás del maléolo interno. Desde dicho punto continúa distalmente dentro de una vaina tenosinovial y finaliza en múltiples inserciones: la cara plantar del escafoides y la cuña medial. El trayecto del tendón es dorsal al eje de rotación del tobillo y medial al eje de la subastragalina; el músculo funciona como un flexor plantar del tobillo e inversor del pie. El músculo tibial posterior inicia la inversión activa del retropié en la articulación subastragalina tras el apoyo plantar completo durante la fase de soporte del ciclo de la marcha (segundo rocker).

A medida que el retropié se invierte, los ejes de las articulaciones astragaloescafoidea y calcáneo cuboidea pierden su paralelismo y el pie pasa de ser flexible durante la fase de contacto del talón a ser rígido en la de despegue. La inserción del tendón de Aquiles se medializa respecto al eje de rotación de la subastragalina, asegurando firmemente la inversión del retropié y la posición de las articulaciones tarsianas transversas: el pie se convierte en una palanca rígida que eleva y propulsa el cuerpo durante las últimas secuencias del apoyo monopodal.

Antagonistas primarios del tibial posterior son los músculos peroneos, que evierten el retropié y abducen el mediopié. El tibial posterior es solicitado durante las fases de soporte del peso de la marcha, mientras que los peroneos actúan evertiendo el pie y desbloqueando las articulaciones tarsianas transversas durante la fase de oscilación, razón por la que éste desarrolla más del doble de fuerza.

Por su parte el tríceps sural al elevar el pie y situarlo en extensión, ejerce su acción sobre el punto de rotura metatarso-falángico al iniciarse el tercer rocker y, al tiempo que levanta el peso del cuerpo, tiende a aplanar la bóveda. Por todo ello, un tibial posterior débil contribuirá a una evolución progresiva hacia el pie plano, con los peroneos manteniendo el pie en eversión y la inserción del tendón de Aquiles lateral al eje de rotación de la articulación subastragalina.

Hicks $^{3}$ describió la bóveda plantar asemejándola a una estructura arquitectónica conocida como «cercha», formada por dos vigas y un tirante representado por la fascia o aponeurosis plantar. También acuñó el concepto de «mecanismo de cabrestante» (windlass) por el que la fascia desarrollaría una acción elevadora sobre la bóveda; al cargar la estructura desde el punto de unión de las vigas, el tirante se opone al colapso, de forma que cuanto menor sea la distancia entre el punto de unión de las vigas y el tirante, menor será el brazo de momento «anticolapso» del mismo. Esto es, cuanto más plano sea un pie, más tensión deberá soportar su fascia plantar para evitar el colapso (Figura 1). Mann postuló posteriormente ${ }^{4}$ que la fascia plantar constituía el principal estabilizador de la bóveda.

Thordarson $^{5}$ tras referir los trabajos de Hicks y su descripción del cabrestante realiza un estudio experimental en pies de cadáver sometidos a cargas y concluye que la aponeurosis plantar mediante la dorsiflexión de los dedos
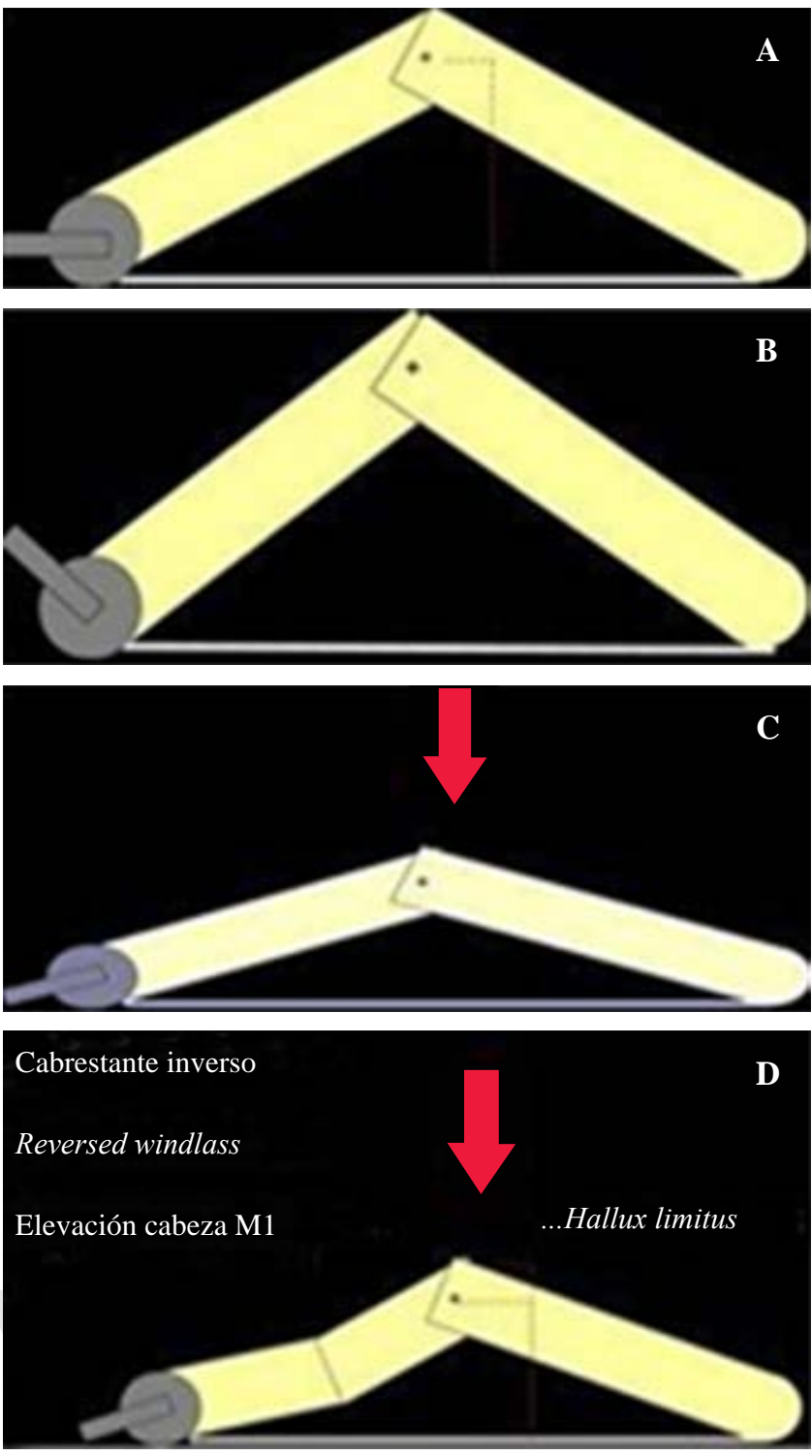

Figura 1: A) Cuanto más plano sea un pie, más tensión deberá soportar la fascia plantar para evitar el colapso. B) En uno de los extremos de la cercha existe un engranaje de tensado del tirante que la convierte en un cabrestante (windlass), de manera que al flexionar dorsalmente el dedo gordo aumenta la flecha del arco. C) La estructura, el arco se aplana y el dedo se estabiliza en el suelo en flexión plantar. D) Mecanismo de cabrestante inverso o reversed windlass. 
representa el principal elemento de soporte en el plano sagital. Coincide con los hallazgos previos de Huang, ${ }^{6}$ quien mediante un estudio experimental en cadáver para obtener un pie plano, comunica una gran actividad de la fascia como soporte estabilizador. Posteriormente Deland ${ }^{7}$ para obtener un pie plano refiere que necesita seccionar la fascia y el ligamento en hamaca.

El ligamento calcáneo escafoideo o en hamaca (spring ligament) al formar parte del acetabulum pedis actúa junto con el tibial posterior como un estabilizador de la cabeza astragalina y del arco longitudinal interno. Para ello se estructura a modo de una lámina fibrosa resistente y cóncava inserta en la apófisis anterior del calcáneo y en el borde inferior y extremidad interna del escafoides, ocupando el espacio triangular existente entre ambos huesos.

Tras un estudio morfológico, histológico y vascular del ligamento, Davis ${ }^{8}$ diferencia dos estructuras o fascículos: una más extensa superointerna y otra inferior, separadas por una pequeña zona triangular. La superior presenta propiedades histológicas adecuadas para resistir solicitaciones a compresión axial pura y por lo tanto, para trabajar cuando el pie esté en vertical sobre el suelo durante la fase propulsiva (tercer rocker); su cara profunda está recubierta por una faceta articular triangular fibrocartilaginosa, avascular, a modo de «cabestrillo» para la cabeza astragalina, estructura presumiblemente configurada para resistir fuerzas de compresión al igual que los meniscos de la rodilla.

Por su parte la porción inferior, por su histología parece desempeñar una función tensil. Una tercera porción o ligamento medioplantar oblicuo calcáneo escafoideo se extiende desde el fascículo anterior del ligamento deltoideo hasta el superior interno del ligamento en hamaca. Campbell ${ }^{9}$ enfatiza dicha unión que, constituyendo una ancha confluencia ligamentosa o «ligamento tibio calcáneo escafoideo», contribuye a estabilizar las articulaciones tibioastragalina y astrágalo escafoidea mediales. Este conjunto ligamentoso determina el denominado «complejo del ligamento en hamaca». El análisis biomecánico sugiere que forma parte del grupo de ligamentos que contribuyen al soporte del arco interno, si bien no es capaz de elevarlo aisladamente.

Kobezda y colaboradores ${ }^{10}$ también atribuyen un papel fundamental en el soporte de la bóveda a la fascia y a los ligamentos plantares. Los resultados de su investigación revelan que la fascia desarrollaría una resistencia en el soporte del arco medial tres veces superior a la del tibial posterior. Por consiguiente, la insuficiencia del mismo precedería al colapso del arco medial.

\section{Función muscular en el pie plano del adulto}

Estudios biomecánicos: es clásico el debate sobre la importancia de la musculatura y los ligamentos en el soporte y elevación de la bóveda plantar. Jones en 1941, ${ }^{11}$ tras analizar experimentalmente pies de 100 cadáveres sin antecedentes patológicos concluyó que: a) Del estrés tensional inicial existente sobre la bóveda, la mayor parte era soportado por los ligamentos plantares, en tanto que los músculos largos no contribuirían en más de 15-20\%. b) Los músculos cortos plantares contribuirían también al soporte del arco longitudinal, ya que debido a su posición y relaciones estarían mejor adaptados para dicha función que la musculatura larga.

Hicks ${ }^{12}$ estudió la repercusión sobre la actividad de la musculatura cuando la bóveda plantar está sometida a carga bajo el peso corporal, concluyendo que variaba dependiendo de la situación del centro de gravedad: era nulo cuando se localizaba en el talón (midiendo la tensión producida sobre la aponeurosis plantar) y aumentaba casi al doble del peso corporal cuando se trasladaba a la cabeza del primer metatarsiano.

Analizando los músculos que podrían presentar acciones directas o indirectas sobre los arcos plantares por su radio de acción sobre las articulaciones que mantienen el equilibrio, concluyó que los músculos actuaban sobre el pie de dos maneras: directamente sobre las articulaciones propiamente dichas o indirectamente por sus efectos en la situación de la línea de gravedad. Así, por ejemplo, el músculo flexor largo del primer dedo y el músculo flexor largo de los dedos tendrían una acción de elevación directa sobre el arco medial, razón por la que el autor distingue los conceptos de «soporte»y «elevación»: en su opinión la musculatura actuaría elevando la bóveda a partir de una posición favorable de la línea de equilibrio corporal, pero no proporcionaría soporte alguno, exceptuando el músculo peroneo largo.

Houtz y Fischer en $1961^{13}$ ratificaron la incidencia de las fuerzas externas y gravitacionales como modificadoras de la función muscular. La cabeza, tronco, brazos y pelvis concurren en una gran variedad de movimientos y la posición de la pierna y el pie se adapta automáticamente.

Más recientemente, Imhauser ${ }^{14}$ mediante un estudio con un modelo in vitro llega a parecidas conclusiones: el tibial posterior tiene una función importante en la traslación ventralmente del centro de presión durante la fase de despegue. Su disfunción podría originar un pie plano.

En el trabajo previamente reseñado de Thordarson, además de la importante función atribuida a la fascia plantar, también confirmaba la del tendón tibial posterior como soporte del arco interno en el plano sagital (además de la aducción del antepié en el plano transverso) tanto bajo cargas de $350 \mathrm{~N}$ como de $700 \mathrm{~N}$. Los músculos flexor largo, flexor del hallux y peroneo largo contribuirían a aumentar el arco interno en el plano sagital. Por su parte el tríceps sural actuaría como aplanador del arco interno bajo carga de $350 \mathrm{~N}$ y adicional con $3.7^{\circ}$, con carga de $700 \mathrm{~N}$, además de abductor en el plano transverso.

Estudios electromiográficos: la introducción de la técnica electromiográfica a partir de los años 40 permitió estudiar la actividad de la musculatura en las diferentes posiciones y movimientos del pie tanto en situaciones estáticas como dinámicas. Basmajian y Stecko en $1963^{15}$ mostraron que la primera línea de defensa de los arcos sería ligamentosa. La musculatura funcionaría a modo de «reserva funcional dinámica», incluyendo la fase de despegue de la marcha. 
En 1975 Núñez-Samper y Gómez Pellico añadieron el concepto de «sobrecarga funcional». ${ }^{16}$ Estudiamos la actividad electromiográfica de cuatro músculos extrínsecos (del tibial anterior, peroneo lateral largo, tibial posterior, gemelo externo) y tres intrínsecos (flexor corto de los dedos, abductor del hallux y abductor del quinto dedo) en pies normales, planos y cavos.

\section{Concluimos que en el pie normal:}

1. La actividad muscular intrínseca en apoyo bipodal es débil y nula en la musculatura extrínseca.

2. Los músculos intrínsecos mostraron la mayor actividad, especialmente el abductor del hallux, seguido del flexor corto de los dedos, ratificando los hallazgos previos de Mann e Inman en $1964 .{ }^{17}$ Aplicando el mismo protocolo estudiamos la actividad de dichos músculos en pies planos y $\operatorname{cavos}^{16,18}$ y hallamos que:

a. En apoyo unipodal la contracción muscular se duplica en los pies normales y cavos se triplica en el pie plano.

b. El músculo abductor del dedo gordo es aquél que desarrolla una mayor actividad en ambos tipos de pies, junto con el peroneo lateral largo en el pie plano, ratificando en este caso los resultados obtenidos por Suzuki. ${ }^{19}$

c. El comportamiento muscular en los pies desestructurados es mucho más similar entre sí que ambos con el pie normal, hecho que interpretamos como un mecanismo de defensa o adaptación secundario al fracaso de las barreras ósea y ligamentosa. Sulowska en $2016^{20}$ ha confirmado recientemente nuestros hallazgos sobre la musculatura corta plantar.

Por su parte Kitaoka ${ }^{21}$ simuló experimentalmente cargas durante la fase unipodal de la marcha, llegó a la conclusión de que la relajación en la presión ejercida sobre el tendón tibial posterior provoca cambios posicionales de las estructuras del pie tendentes a restaurar el alineamiento del arco plantar interno; infiere que «es un estabilizador importante del arco plantar». Dullaert ${ }^{22}$ analiza mediante un estudio biomecánico experimental del tendón tibial posterior en pies de cadáveres sometidos a carga axial, analizados con tomografía axial, el colapso del arco medial y la subluxación de la articulación subastragalina como hallazgos habituales del pie plano. Concluyen contrariamente que el tibial posterior bajo carga no restaura el arco plantar medial ni corrige la subluxación subastragalina ni el ángulo astrágalo metatarsal.

Estudios clínicos: Borton y Saxby ${ }^{23}$ en 1997 comunicaron un caso de clínica compatible con patología del tibial posterior y hallazgo quirúrgico de rotura del ligamento en hamaca. La reparación del ligamento y refuerzo con el músculo flexor largo permitió la reincorporación del paciente a sus actividades deportivas. Kadakia ${ }^{24}$ realizó una evaluación radiológica en proyección lateral para determinar si la deformidad del pie plano se debe preferentemente a un fallo de la columna medial del arco interno o bien a una auténtica subluxación periastragalina con el objeto de valorar la mejor opción terapéutica, sugiriendo al final la estabilización del retropié, incluyendo la reconstrucción del ligamento medial y/o el ligamento en hamaca.

Gazdag y Cracchiolo ${ }^{25}$ relacionan la ruptura del tendón y consiguiente pérdida de la inversión normal del retropié con la hiperactividad del músculo tríceps sobre la articulación astragaloescafoidea, que provocaría tensión sobre la cabeza astragalina y lesión del ligamento en hamaca. Analizan su casuística de 22 pacientes a los que se había realizado una reparación y refuerzo del tendón tibial posterior, comunicando que en 18 casos existía una lesión del ligamento en hamaca, que variaría desde la distensión o ruptura longitudinal hasta la rotura completa del mismo. Por ello, aconsejan la búsqueda y en su caso reparación del ligamento en hamaca al tiempo que el tendón tibial posterior.

Orr y Nunley ${ }^{26}$ comunican seis casos de pies planos adquiridos sin lesión del tendón en los que asociaban roturas del ligamento en hamaca. A la reparación del ligamento, con o sin cirugía reconstructiva añadida del pie plano, siguió la corrección completa de la deformidad con un solo paciente que se quejaba de dolor residual. Por ello, aconsejan descartar una lesión aislada del ligamento como posible origen del pie plano para evitar un tratamiento incorrecto.

Considerando la osteotomía varizante de calcáneo como uno de los procedimientos habituales en el tratamiento del pie plano adquirido en el adulto, Larrainzar ${ }^{27}$ estudia su efecto en los tejidos blandos que soportan el arco plantar mediante un modelo computacional por elementos finitos del pie humano, diseñado con un enfoque clínico a partir de tomografías computarizadas de un pie sano. Se incluyeron todos los huesos, la fascia plantar y el ligamento en hamaca, cartílagos y demás ligamentos plantares, respetando su distribución morfológica y propiedades biomecánicas y emulando la fase de apoyo monopodal de la marcha. Los resultados muestran que la osteotomía de calcáneo reduce la tensión generada sobre los tejidos evaluados, especialmente sobre la fascia y del ligamento en hamaca. La rotura de éste provoca un aumento de $9.1 \%$ de caída del arco plantar y muy especialmente, una variación del ángulo de Kite de $88.9 \%$, con el consiguiente aumento notable de la pronación del pie, es decir, que la función clave del ligamento sería preferentemente la de «mantener la divergencia astrágalo calcánea más que sobre el aplanamiento plantar». Estos datos, unidos al escaso papel de los ligamentos plantares corto y largo en el mantenimiento del arco plantar interno, coinciden con el trabajo previo ya reseñado de Huang y muestran la validez de la predicción matemática del modelo. Una predisposición en la forma o una tendencia al pie plano pueden contribuir a explicar también la patogenia de la disfunción del tendón, así como los fracasos a largo plazo de las transferencias del flexor común o del propio al tibial posterior patológico cuando coexista una alteración biomecánica del pie.

En este sentido, Greisberg y colaboradore ${ }^{28}$ atribuyen algunos casos de pie plano a una inestabilidad primaria de la columna medial sin afectación de la articulación astrágalo escafoidea. 
Valora clínica y radiológicamente los resultados obtenidos tras el realineamiento de la columna mediante con una modificación de la técnica de Miller, añadiendo al adelantamiento (y en su caso reconstrucción) del tibial posterior, una artrodesis localizada (escafo-cuneana y/o cuneo-metatarsiana) y alargamiento del tríceps. Aconsejan este procedimiento en casos seleccionados y/o en los que una osteotomía calcánea varizante presumiblemente no sea suficiente para corregir la deformidad en los planos axial y sagital.

\section{Patogénesis}

\section{Disfunción del tibial posterior, ¿problema} primario o secundario?

Errichiello en 2008 (Chirurgia del Piede V32, N3) refiere «...la disfunzione del Tibiale posteriore predispone al piede plato acquisito...il piede plato acquisito predispone alla disfunzione del Tibiale posteriore...»

A este respecto el autor agrupa los diferentes orígenes en tres grupos:

1. Disfunción del tibial posterior causante de un pie plano adquirido del adulto.

2. Pie plano adquirido del adulto causante de una disfunción del tibial posterior.

3. Disfunción del tibial posterior asociada con otros factores que causen un pie plano doloroso del adulto.

Yeap y colaboradores ${ }^{29}$ también se preguntan si la disfunción es un problema primario o secundario. Tras el seguimiento de 16 transferencias de dicho tendón para recuperar una dorsiflexión activa, sugieren que el tratamiento de la disfunción grado II debe basarse en la corrección de la biomecánica del pie más que en la simple transferencia o refuerzo del mismo. En su casuística refieren pacientes en los que las posibilidades de elevarse de puntillas con diversos grados de supinación del tobillo pueden atribuirse a la acción del flexor largo de los dedos o flexor del hallux, ambos con recorrido medial al eje de la subastragalina o bien a la inversión pasiva o «cercha inversa» de la fascia plantar ya mencionada. En consecuencia, la insuficiencia o pérdida de elevación del talón no significaría forzosamente un signo de rotura del tendón, sino que puede deberse a un bloqueo antiálgico por sinovitis del mismo o bien a una inestabilidad global del tarso, secundaria a la tensión ejercida sobre el soporte ligamentoso del propio ligamento e incluso de la fascia plantar. La resonancia magnética nos permitirá el diagnóstico diferencial de lesiones ligamentosas primarias como alternativa a una disfunción del tibial posterior. ${ }^{30}$

Tryfonidis ${ }^{31}$ presenta nueve casos de pie plano secundarios a insuficiencia aislada del ligamento en hamaca diagnosticada por ultrasonidos. Williams ${ }^{32}$ investigó en 161 pacientes la posible asociación de hallazgos patológicos del ligamento y del tendón mediante un estudio comparativo radiológico por resonancia magnética (RM). Concluyen que en los casos de pies planos valgos con afectación radiológica importante analizados por RM existían al menos los mismos signos de anormalidad del ligamento que del tendón.

Tras un estudio experimental biomecánico en 21 especímenes Pasapula ${ }^{33,34}$ concluye que la integridad del ligamento es fundamental para impedir la aparición de un pie plano, razón por la cual los sistemas tradicionales de reparación pueden fracasar a largo plazo. Describe un signo específico para detectar la lesión o «prueba de empuje neutral» que mide su resistencia al empuje lateral: si cede, la cabeza astragalina tenderá a subluxarse medialmente y a ejercer presión sobre el tendón, presionándolo mecánicamente por un «efecto de polea», originando una sinovitis del mismo como lesión inicial. Secundariamente se seguiría de una sobrecarga medial con fallo progresivo del tendón.

En consecuencia, los autores proponen una nueva clasificación de la insuficiencia del arco medial basada en el fallo inicial del ligamento en hamaca de forma progresiva y consecutivamente, de los ligamentos tarso-metatarsales del primer radio y ligamento deltoideo. Por lo tanto, el diagnóstico de la existencia de una lesión previa del complejo ligamentario plantar deberá plantearse como una pauta clínica habitual ante una deformidad del pie plano adulto.

\section{Factores etiopatogénicos}

\section{Origen degenerativo}

Pisani ${ }^{35}$ subraya la importancia de la patología degenerativa del ligamento en hamaca en la patogénesis del pie plano del adulto, refiriéndose a la «glenopatía degenerativa primaria» sin afectación previa del tendón, afirmando que la estructura glenoidea forma parte del componente cotiloideo del acetabulum de la coxa pedís. También considera la relación de dicha estructura con el hallazgo del hueso accesorio escafoideo que, situado entre el tendón y la glenoide, podría estar sometido a un mecanismo lesional por microtraumatismos directos.

Brodell ${ }^{36}$ también comunica la rotura habitual del ligamento en los estadios avanzados de pie plano. La íntima relación normofuncional del fascículo superficial del ligamento deltoideo con la porción superointerna del ligamento en hamaca (ligamento astrágalo calcáneo escafoideo) descrito por Campbell como estabilizadores de la columna medial, convierten su fallo ante un aumento de tensión sobre el conjunto ligamentoso en una inestabilidad periastragalina progresiva y una posible insuficiencia del ligamento deltoideo. Preconiza consecuentemente la reconstrucción del conjunto deltoides-ligamento en hamaca en estadios avanzados del pie plano del adulto.

\section{Factores biomecánicos}

Como hemos revisado previamente, el pie plano adulto proviene genéricamente de factores extrínsecos o intrínsecos. Los extrínsecos incluyen enfermedades o deformidades 
que indirectamente provoquen alteraciones mecánicas en los tejidos o articulaciones. Los intrínsecos son secundarios a patologías del pie (especialmente la elongación y/o ruptura degenerativa espontánea del tibial posterior) o de estructuras que actúan a distancia sobre el mismo.

\section{Origen extrínseco:}

a. Se señalan factores generales de riesgo diverso, entre los que destacan la edad y el género femenino en $70 \%$ de los casos, estrés crónico sobre ligamentos hiperlaxos, obesidad con hipertensión, diabetes, entesopatías, colagenosis o artritis seronegativas, ${ }^{37}$ soriasis, síndrome de Reiter, espondilitis anquilosante, artropatía de Charcot y enfermedades neuromusculares.

b. La hipótesis de traumatismos agudos previos suele confirmarse en casos de fracturas maleolares, Funk y colaboradores. ${ }^{38}$ refieren hasta $50 \%$ de dicho antecedente en población joven. En general, parecen ser más numerosas las anomalías o factores biomecánicos intrínsecos que los extrínsecos traumáticos.

2. Origen intrínseco:

Dentro de las causas intrínsecas, si analizamos algunas de las clasificaciones propuestas, en cierto modo asistimos a una «vuelta de rosca» sobre las teorías biomecánicas que explican el mantenimiento de la bóveda plantar.

a. En la mayoría de los casos se atribuye a la debilidad de la musculatura y más concretamente del tendón tibial posterior, sumada o no a la hipertonía de los peroneos y/o del tríceps sural. Algunos autores señalan la relación de la lesión del tendón tibial posterior con su vascularización.

Frey y colaboradores ${ }^{39}$ identificaron un área de hipovascularidad intratendinosa detrás del maléolo medial a la que atribuyeron una predisposición a la degeneración y tendinopatía secundaria, especialmente en pacientes adultos. Sin embargo, un gran porcentaje de anomalías del tendón tibial posterior aparecen distales a esta región. Más recientemente, Prado y su equipo ${ }^{40}$ realizan un estudio en 80 tendones humanos (40 de cada sexo) sin signos previos de lesión vascular, antecedentes diabéticos o traumáticos. Utilizan la técnica de tricrómico de Masson y el método de visualización de Weibel para obtener la densidad vascular en cada corte transverso y analizar seis niveles de corte (zona de transición miotendinosa, vincula proximal, zonas retromaleolar e inframaleolar, vinculadistal e inserción escafoidea), concluyendo que no existen áreas hipovasculares en las zonas de lesión más frecuentes del tendón tibial posterior.

b. Otras etiologías conocidas incluyen la preexistencia de pies planos congénitos o adquiridos, lesión traumática de los ligamentos del mediopié, coalición tarsal no diagnosticada o artrosis tarsometatarsiana. Viladot Voegeli A. refiere en «Anatomía, biomecánica y patofisiología del pie plano adulto» que la mayoría es de origen mecánico y aparece frecuentemente en pacientes con un pie plano previo que no fue tratado en la infancia.
También se ha asociado la disfunción del tibial posterior con la inyección de corticosteroides en la vecindad de la vaina tendinosa y con la gonartrosis en valgo homolateral.

c. Los estadios avanzados de pie plano se caracterizan por la existencia de un aumento de las fuerzas actuantes sobre el ligamento en hamaca y los ligamentos interóseos, con la instauración de una inestabilidad periastragalina progresiva y posible insuficiencia en paralelo del ligamento deltoideo.

De ahí la importancia de restaurar la biomecánica del complejo en el tratamiento de la deformidad. ${ }^{39}$ En el referido trabajo de Davis ${ }^{8}$ se sugiere la existencia de una auténtica sinergia entre la unidad dinámica representada por el tibial posterior y la estática por el ligamento para impedir la desviación plantar y medial de la cabeza astragalina y consecuentemente, la defectuosa transmisión de cargas a través del acetabulum pedis ${ }^{40} \mathrm{y} / \mathrm{o}$ de las zonas más solicitadas del arco medial y su posible colapso (inestabilidad primaria de la columna medial). ${ }^{28}$

En este sentido, resaltamos los trabajos ya referidos de Larrainzar, quien preconiza la función de los ligamentos como mantenedores de la divergencia astrágalo calcánea (más que como soportes estáticos) y los de NúñezSamper (tesis doctoral), ${ }^{16}$ sobre el comportamiento y respuesta electromiográfica de los músculos extrínsecos e intrínsecos del pie plano, donde demostró que sólo con $40 \%$ de actividad muscular, los músculos abductor del primer dedo y peroneo largo colaboraban al soporte de la bóveda plantar del pie plano. Por el contrario, el tibial posterior ofrecían muy bajos registros y pobre respuesta en situaciones estáticas. ${ }^{41}$

\section{Estadios clínicos. Clasificación}

Johnson y Strom en $1989^{2}$ tipificaron la deformidad en tres fases, posteriormente Bluman, Title y Myerson en $2007^{42}$ (Tabla 1) y Haddad en 2011 la clasificaron en cuatro estadios en función de la evolución del proceso y la anatomía patológica de la lesión.

Raikin en $2012^{43}$ propone una nueva clasificación para la disfunción del tibial posterior o clasificación RAM, que desglosa la deformidad en partes individuales que están implicadas en el proceso: Rearfoot, Ankle y Midfoot, (por sus siglas en inglés RAM) (Tabla 2).

Cada parte está dividida en tres estadios que a su vez están subdivididos en subgrupos que describen las diferentes fases del proceso.

Pasapula en 2018 describe una clasificación en cuatro estadios basada en el fallo de la columna medial. Propone una clasificación en etapas que se centra en la lesión del ligamento en hamaca y refiere que si se produce una tendinopatía que va a derivar en un pie plano inestable, «debería haber una etapa previa» donde se rompe el ligamento en hamaca.

R. Viladot en 2001 publica también una clasificación ${ }^{44}$ que divide en tres estadios: 
1. Estadio sinovial.

2. Fase tendinosa.

3. Lesiones óseas.

Las tres fases vienen a representar la etiopatogenia de la deformidad.

\section{Resumen práctico}

Estadio I: incluye a todos aquellos pacientes con hipersensibilidad, dolor y tenosinovitis con o sin tendinopatía, pero sin deformidad.

Estadio II: los pacientes tienen una deformidad dinámica, flexible, con algún grado de alteración de la alineación del retropié, pérdida del arco longitudinal medial y abducción del antepié.

Estadio III: se caracteriza por un retropié fijo en valgo, acompañado de una deformidad del antepié en supinación para mantener el pie plantígrado. Al ser un proceso evolutivo, en estadios previos (II y III) ya se empieza a asociar progresivamente la rigidez del tríceps sural (gastrocnemio y/o sóleo), el acortamiento del tendón de Aquiles y la limitación de la flexión dorsal e inversión del pie.

Estadio IV: a medida que el tendón tibial posterior pierde su función, el arco longitudinal medial se colapsa, lo que provoca una rotación interna relativa de la tibia y del astrágalo. ${ }^{37}$ Hay eversión de la articulación subastragalina que fuerza el talón en valgo y desviación de la articulación astragaloescafoidea, llegando a ser ineficaz la función del ligamento deltoideo. La aparición de fenómenos artrósicos y pérdida de elasticidad se va haciendo cada vez más manifiesta (estadio IV-A y IV-B).

A medida que la deformidad empeora, el peroné distal entra en contacto con el lateral del calcáneo, provocando dolor permanente en la parte posterior del pie.

En ambos casos IV-A y IV-B, el retropié se orienta en valgo así como la articulación tibiotalar. En el estadio IV-B el astrágalo tiende a luxarse fuera de la mortaja por la situación en valgo del calcáneo y por la incompetencia por laxitud o rotura del ligamento deltoideo. El antepié se aduce y la articulación metatarso falángica se dispone en valgo produciéndose un hallux valgus.

En estos estadios, al ser la deformidad muy manifiesta, el diagnóstico es fundamentalmente clínico. A la exploración física, la debilidad del tendón se objetiva por la disminución de la fuerza inversora del retropié, ya sea con el paciente sentado en la camilla o de pie. Hay en mayor o menor grado disminución del tono muscular, que se evidencia con el paciente en decúbito dorsal, por la posición espontánea del pie en menor inversión y supinación que en el lado contralateral.

La falta de homogeneidad muscular es indicativa de rotura parcial o tendinopatía crónica.

Para confirmar el diagnóstico clínico, realizaremos pruebas funcionales que confirmen el diagnóstico. Los signos de «demasiados dedos» (Keneth Johnson), «Rodríguez Fonseca» $\mathrm{y}$ «elevación del primer metatarsiano» son las pruebas habitualmente empleadas.
Tabla 1: Clasificación de Bluman, Myerson y Title.

\begin{tabular}{|c|c|c|}
\hline Estadio & Subtipo & \\
\hline \multirow[t]{6}{*}{ I } & \multirow[t]{2}{*}{ A } & Anatomía normal \\
\hline & & Dolor TTP \\
\hline & \multirow[t]{2}{*}{ B } & Anatomía normal tendinosis \\
\hline & & Dolor TTP \\
\hline & \multirow[t]{2}{*}{$\mathrm{C}$} & Retropié valgo leve \\
\hline & & Dolor TTP \\
\hline \multirow[t]{19}{*}{ II } & \multirow[t]{5}{*}{ A1 } & Retropié valgo flexible \\
\hline & & Antepié varo flexible \\
\hline & & Disrupción línea Meary \\
\hline & & Posible dolor TTP \\
\hline & & Pérdida de inclinación de calcáneo \\
\hline & \multirow[t]{5}{*}{ A2 } & Retropié valgo flexible \\
\hline & & Antepié varo rígido \\
\hline & & Disrupción línea Meary \\
\hline & & Dolor TTP \\
\hline & & Pérdida de inclinación de calcáneo \\
\hline & \multirow[t]{3}{*}{ B } & Retropié valgo flexible \\
\hline & & Decoaptación astragaloescafoidea \\
\hline & & Abducción antepié \\
\hline & \multirow[t]{6}{*}{$\mathrm{C}$} & Retropié valgo flexible \\
\hline & & Antepié varo rígido \\
\hline & & Gap plantar primera TMT \\
\hline & & Inestabilidad columna medial \\
\hline & & Dorsiflexión primer radio con corrección RP \\
\hline & & Dolor seno del tarso \\
\hline \multirow[t]{9}{*}{ III } & \multirow[t]{4}{*}{ A } & Retropié valgo rígido \\
\hline & & Pérdida de EA subastragalina \\
\hline & & Dolor seno del tarso \\
\hline & & Esclerosis ángulo de Gissane \\
\hline & \multirow[t]{5}{*}{ B } & Retropié valgo rígido \\
\hline & & Pérdida de EA subastragalina-antepié \\
\hline & & Dolor seno del tarso \\
\hline & & Esclerosis Gissane \\
\hline & & Abducción antepié \\
\hline \multirow[t]{4}{*}{ IV } & \multirow[t]{2}{*}{ A } & Valgo tibioastragalino flexible \\
\hline & & Retropié valgo \\
\hline & \multirow[t]{2}{*}{ B } & Valgo tibioastragalino rígido \\
\hline & & Retropié valgo \\
\hline
\end{tabular}

TTP = Tendón del tibal posterior; TMT = Tarso-metatarsiano; RP = Retropié; $\mathrm{EA}=$ Espacio articular.

Los pacientes con disfunción del tibial posterior en el estadio III y IV son incapaces de ponerse de puntillas con un único talón sin apoyo ipsilateral, es decir, no pueden pasar de la posición bipodal a monopodal.

El signo de «Rodríguez Fonseca» representa la persistencia del valgo de talón al ponerse de puntillas sobre uno o dos pies. El signo de «demasiados dedos» cuantifica la abducción del antepié por la presencia de muchos dedos por fuera al explorar el pie desde atrás y el signo de «elevación del primer metatarsiano» se considera positivo cuando la pierna al realizar un movimiento de rotación externa, aparece una pérdida de contacto de la cabeza del primer metatarsiano con el suelo.

Los tres signos van a ser patentes en los estadios III, IV-A y IV-B en mayor o menor grado.

La progresión de la deformidad no es necesariamente un proceso lineal y puede comprometer diferentes zonas alrededor del pie y del tobillo de diversas maneras y en diversos grados. 
Cada disfunción del tibial posterior no siempre es consistente con el sistema de clasificación convencional. Esta inconsistencia puede servir como una fuente de confusión cuando se trata de asignar a un paciente un grado para definir el tratamiento específico.

Además de estas clasificaciones hay que reseñar la clasificación de Cracchiolo de $1997^{25}$ en la que refiere cinco estadios: el tipo 1 afectación de gastrocnemios, el tipo 2 con afectación de antepié, el tipo 3 afectación de mediopié, el tipo 4 afectación de retropié y el tipo 5 cuando el tobillo está afectado. Esta clasificación y la de Pasapula ${ }^{34}$ son poco utilizadas.

En la actualidad la más empleada es la clasificación de Bluman, Myerson y Title por ser la más completa y valorar en sus diferentes estadios de forma conjunta la deformidad ósea y la lesión del tendón tibial posterior. Con base en la clasificación de Johnson y Strom, Myerson modificó el sistema con la adición de una cuarta etapa más avanzada de la enfermedad. Esta etapa describe la afectación de la articulación tibiotalar además de la mala alineación del retropié que se observa en las etapas II y III. Esta etapa más avanzada se compone de una deformidad en el valgo del retropié como resultado de la degeneración del tendón tibial posterior, con la inclinación del valgo asociada del astrágalo dentro de la mortaja, dividiéndola en dos subgrupos en función de la rigidez o no de la articulación.

\section{Técnicas de tratamiento}

\section{Transferencias tendinosas}

La modificación de las fuerzas equilibrantes de la musculatura extrínseca causa déficit en la cinética de las articu- laciones de medio y retropié, llevando a máxima contención las estructuras capsuloligamentarias de la articulación de Chopart y subastragalina, que sumadas a la fuerza del tendón de Aquiles durante la marcha someten a mayor tensión el complejo capsuloligamentario medial lesionando el ligamento en hamaca y de forma secundaria causando inflamación y ruptura del tibial posterior y alteraciones en su inserción. ${ }^{22,45}$

Dullaert ${ }^{22}$ demostró que la tensión aislada del tendón tibial posterior no corrige la deformidad del plano en bipedestación, al contrario la aumenta y sólo la activación simultánea de los estabilizadores activos y pasivos logrará un pie plantígrado.

Sobre la misma línea se encuentran los trabajos de Jennings y Christensen, quienes describen que la sección aislada del ligamento en hamaca que ocasiona deformidad de pie plano y la tensión aislada del tendón tibial posterior no logran el pie plantígrado, demostrando que el músculo tibial posterior sólo actúa como principal inversor del pie durante la fase de despegue.

Esto es debido a que durante la fase de apoyo la inserción del tibial posterior se encuentra distal a los ejes articulares del retropié. Mientras que en la fase de despegue el pie se encuentra en flexión plantar, el astrágalo rota externamente y el brazo de palanca del tibial posterior actúa de forma eficiente. ${ }^{46}$

El tratamiento debe dictarse al entender la complejidad de su origen; haber estadificado la enfermedad con el objetivo de recuperar la alineación del pie, reconocer y tratar el equino, corregir adecuadamente la deformidad del retropié para permitir restablecer la dirección de las fuerzas a través del tendón de Aquiles, con la alineación medial al eje de la articulación subastragalina y con la adecuada orientación de

\begin{tabular}{|c|c|c|c|}
\hline & Retropié & Tobillo & Mediopié \\
\hline IA & Tenosinovitis del TTP & Alineación neutra & Alineación neutral \\
\hline IB & Tendinitis del TTP, sin deformidad & Valgo leve (menor de $5^{\circ}$ ) & Supinación leve flexible \\
\hline IIA & $\begin{array}{l}\text { Pie plano valgo flexible, } \\
\text { descubrimiento del astrágalo }<40 \% \text {, } \\
\text { ángulo Meary }<30^{\circ} \text {, ángulo de } \\
\text { incongruencia: de } 20^{\circ} \text { a } 45^{\circ}\end{array}$ & $\begin{array}{l}\text { Valgo con insuficiencia del deltoideo } \\
\text { (sin artrosis) }\end{array}$ & $\begin{array}{l}\text { Supinación del mediopié sin } \\
\text { inestabilidad radiográfica }\end{array}$ \\
\hline IIB & $\begin{array}{l}\text { Pie plano valgo flexible, } \\
\text { descubrimiento del astrágalo }>40 \% \text {, } \\
\text { ángulo Meary }>30^{\circ} \text {, ángulo de } \\
\text { incongruencia }>45^{\circ}\end{array}$ & $\begin{array}{l}\text { Valgo con insuficiencia del deltoideo } \\
\text { (con artrosis tibioastragalina) }\end{array}$ & $\begin{array}{l}\text { Supinación del mediopié con } \\
\text { inestabilidad. Sin artrosis }\end{array}$ \\
\hline IIIA & $\begin{array}{l}\text { Pie plano valgo rígido artrósico, } \\
\text { descubrimiento del astrágalo }<40 \% \text {, } \\
\text { ángulo Meary }<30^{\circ} \text {, ángulo de } \\
\text { incongruencia: } 20^{\circ} \text { a } 45^{\circ}\end{array}$ & $\begin{array}{l}\text { Valgo secundario pérdida ósea en } \\
\text { la epífisis lateral tibial (deltoideo } \\
\text { normal) }\end{array}$ & $\begin{array}{l}\text { Cambios artrósicos aislados en la } \\
\text { columna medial (escafoides-curia } \\
\text { medial o primera cúneo-metatarsiana) }\end{array}$ \\
\hline IIIB & $\begin{array}{l}\text { Pie plano valgo rígido artrósico, } \\
\text { descubrimiento del astrágalo }>40 \% \text {, } \\
\text { ángulo Meary }>30^{\circ} \text {, ángulo de } \\
\text { incongruencia }>45^{\circ} \text {, no corregible } \\
\text { mediante triple artrodesis }\end{array}$ & $\begin{array}{l}\text { Valgo secundario pérdida ósea en la } \\
\text { epífisis lateral tibial con insuficiencia } \\
\text { del deltoideo }\end{array}$ & $\begin{array}{l}\text { Artrosis en la columna medial y } \\
\text { media (habitualmente con supinación } \\
\text { y abducción del mediopié) }\end{array}$ \\
\hline
\end{tabular}




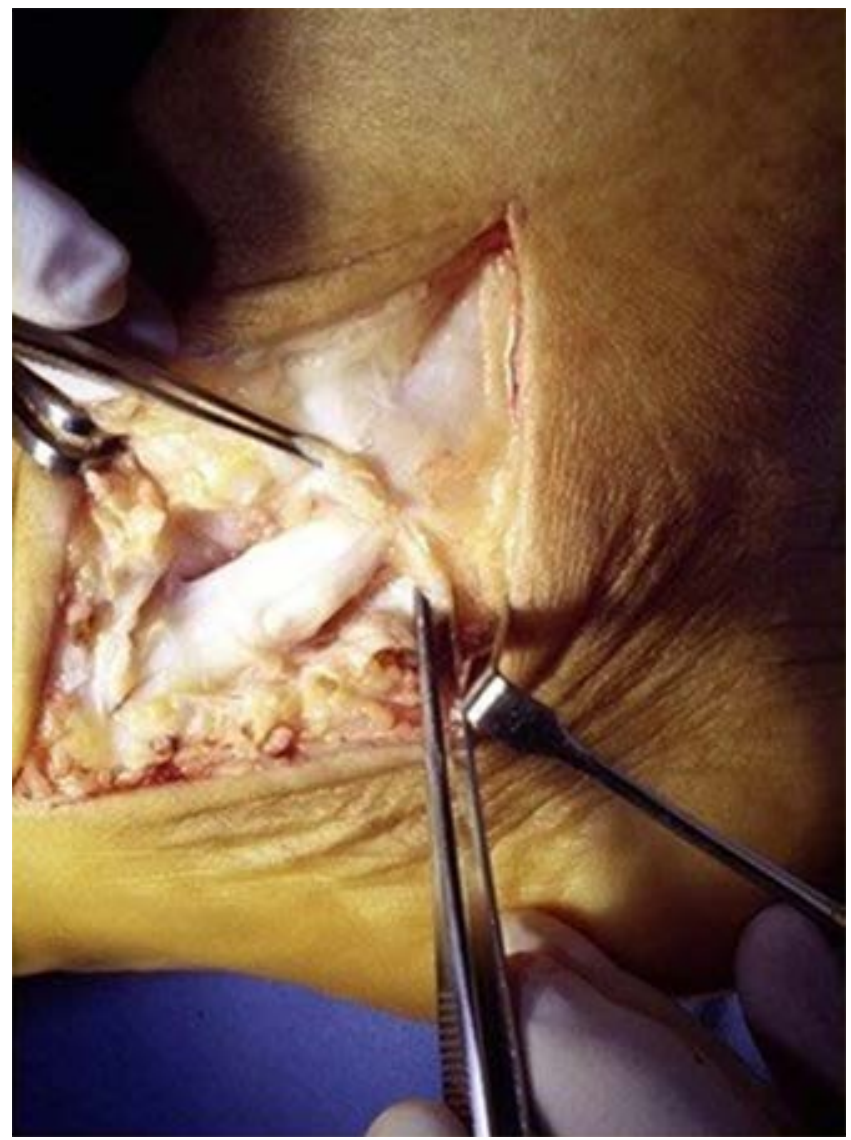

Figura 2: Tenosinovectomía del tibial posterior.

la columna medial, siendo ésta mecánicamente el apoyo del astrágalo.

Por último, corregir el valgo del talón cuidando siempre de no llegar a una sobrecorrección en varo para prevenir la sobrecarga en la barra lateral. ${ }^{47}$

\section{Procedimientos de actuación en los tejidos blandos}

Están indicados en etapas iniciales, concretamente en los estadios I y II, cuando las alteraciones anatómicas y biomecánicas son sutiles.

Al ser una deformidad flexible, el objetivo es devolver el balance muscular corrigiendo el valgo del retropié y limitando la abducción del antepié. ${ }^{48}$ El dolor mecánico se encuentra asociado a un pie en equino en $96 \%$ de los casos, deformidad que puede ser causa de pronación de las articulaciones subtalar y mediotarsal que modifican el eje tibio calcáneo.

El alargamiento del tendón de Aquiles es la técnica de elección. ${ }^{49}$ Hibbs describió por vez primera el alargamiento del complejo suro-aquíleo-calcáneo como tratamiento complementario del pie plano valgo adquirido. ${ }^{50}$

Actualmente existen diferentes técnicas que mantienen la indicación de procedimiento complementario según la severidad de la patología y la reductibilidad de la deformidad.
Es importante realizar una adecuada exploración del sistema aquíleo calcáneo plantar para determinar si el equino se debe al complejo gastrosóleo o gastrocnemio usando el test de Silverskiold (ver apartado de Artrorrisis) para valorar la conducta terapéutica a seguir.

En caso de que los gastrocnemios sean los responsables de la contractura en equino, se realizará una liberación del gastrocnemio medial, procedimiento que ha mostrado resultados satisfactorios..$^{51}$

Cuando la deformidad se debe a los gastrocnemios y al sóleo; la técnica de Strayer y el alargamiento percutáneo son técnicas de elección. ${ }^{51}$ Se debe enfatizar que el uso de estos procedimientos en forma aislada se considera insuficiente, debido a que no alinean por completo la posición del calcáneo y no tienen repercusión en la realineación del mediopié. Las publicaciones consultadas recomiendan realizar de forma sistemática la elongación del tríceps sural como parte de la técnica quirúrgica de tratamiento para lograr la corrección. La falla en reconocer y tratar dicha deformidad tendrá como consecuencia una deformidad residual.

Otra técnica muy utilizada es la tenosinovectomía indicada en pacientes sintomáticos, cuya clínica sea compatible con patología del tendón y la resonancia muestre tendón íntegro con proceso inflamatorio (Figura 2). Este procedimiento tiene indicación como técnica asociada no como técnica aislada y ha evolucionado hacia la tenoscopía ${ }^{49}$ que permite realizar exploración y desbridamiento del tendón a través de pequeñas incisiones, cosméticamente mejor aceptadas, con menos dolor, menores complicaciones y no requiere inmovilización prolongada, pero con la desventaja de que dificulta la completa visualización del tendón. Sin embargo, tampoco trata la patología mecánica, por lo que se ha empleado asociada a otros procedimientos quirúrgicos de mayor rango como la artrorrisis subastragalina, procedimiento que se expondrá a continuación. ${ }^{48,52,53,54}$ (Ver apartado de Artrorrisis).

Si la lesión ocurre en la región distal y el cuerpo del tendón se encuentra en adecuadas condiciones, la técnica principal es el adelantamiento o avance (Figura 3), el cual puede ser complementado con tenodesis «lado a lado»o término-terminal. ${ }^{48}$

Cuando la patología insercional se acompaña de elongación o lesión del propio tendón, el adelantamiento al escafoides o a la primera cuña, con la finalidad de dar soporte medial, limita la abducción a través del peroneo corto que a su vez eleva la columna lateral y evierte el talón. En casos en los que las lesiones se encuentren en el cuerpo del tendón o cuando el tendón está intacto, pero débil o elongado se debe realizar una tenodesis del tibial con el flexor largo de los dedos (Keneth Johnson) como técnica de aumentación o bien la reinserción del tendón tibial posterior (Figura 4). 48,55

Mann y Thompson demostraron que la apertura de la vaina, tenosinovectomía, desbridamiento y transferencia del flexor del primer dedo y el avance de la inserción son técnicas que alivian el dolor y mejoran la función de forma 
temporal. Sin embargo, no logran una adecuada corrección estructural atribuyendo a esta deficiencia las fallas del tratamiento a corto plazo y aumento de la deformidad estructural, motivo por el que se deben complementar con procedimientos óseos, osteotomías del calcáneo, alargamiento de la barra lateral o doble osteotomía. ${ }^{56}$

Durante los años 90 y dando por hecho que el tendón del tibial posterior estaba afectado o era incompetente, el tratamiento se enfocó en que las transferencias tendinosas reemplazaban la fuerza del tendón tibial posterior o lo potencializaban.

En estos casos la transferencia se realiza con el flexor largo de los dedos (Keneth-Johnson) porque es el más accesible de los flexores y disminuye la pronación además de la accesibilidad para obtenerlo, ${ }^{57}$ aunque algunos autores llegan a usar el flexor del hallux. La técnica se realiza a través de un abordaje posteromedial siguiendo la trayectoria del tendón, se identifica, evalúa y desbrida el tibial posterior hasta el área proximal. Se identifica el flexor largo de los dedos, se libera lo más distal posible para lograr longitud y facilitar la transposición. Cuando las alteraciones son en el área proximal del cuerpo del tendón, la transposición se realiza de región perimaleolar a escafoides, respetando la anatomía y mecánica habitual. En caso de que se requiera aumentar el brazo de palanca, la trasferencia debe realizarse a la segunda cuña empleando en ambos casos diferentes métodos de fijación que van desde la sutura al mismo mediante pequeños arpones hasta tornillos interferenciales. ${ }^{55}$ Habitualmente son procedimientos mixtos sobre el flexor largo de los dedos y artrodesis.

Hintermann en 1999 publica 19 casos con disfunción del tibial posterior en los que realizó reconstrucción de tejidos blandos de la columna medial y alargamiento de la columna lateral con buenos resultados.

A partir del año 2006 la tendencia quirúrgica fue el alargamiento de la columna lateral y el uso de endortesis para el seno del tarso con transferencia del tendón flexor largo de los dedos.
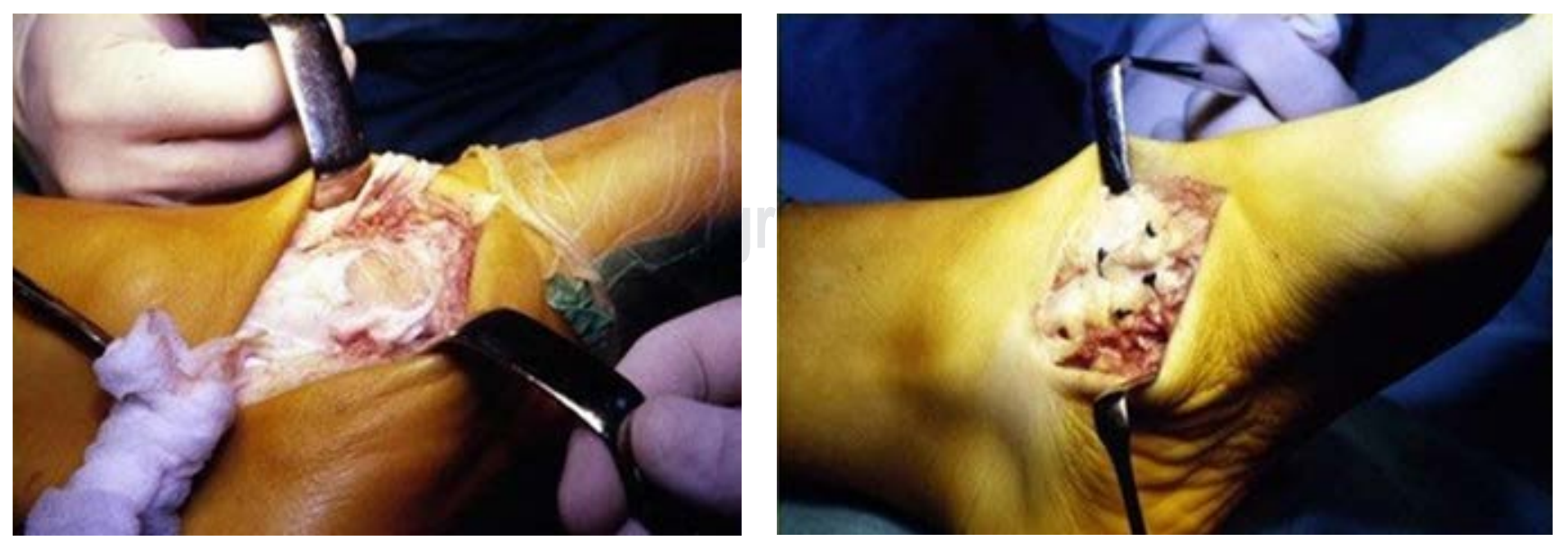

No existe suficiente literatura para recomendar un procedimiento sobre otro. Los seguimientos de las diferentes técnicas para el tratamiento de esta patología y su seguimiento han evidenciado que el tratamiento para el estadio II, las técnicas que combinan procedimientos en tejidos óseos y transferencias tendinosas son las que proporcionan mejores resultados. ${ }^{58}$

Los estudios de seguimiento de los tratamientos con el uso de tejidos blandos para tratar el pie plano del adulto han dado importancia a las estructuras mediales. El estudio en cadáver nos evidencia la importancia del ligamento en hamaca como responsable de las deformidades residuales y fallas en el tratamiento, al mismo tiempo que compara el uso de transferencias tendinosas con sistemas de aumentación interna con fibras sintéticas. ${ }^{33}$

Es de gran importancia evaluar la estabilidad medial del tobillo y el ligamento en hamaca y en caso necesario reconstruir el ligamento deltoideo como complemento a la reparación del ligamento en hamaca y hacer el complejo medial estructural y biomecánicamente competente. ${ }^{33,57}$

En la actualidad existe una tendencia del tratamiento a recuperar la estructura en los ejes de movimiento mediante procedimientos a estructuras óseas como la osteotomía de medialización del calcáneo (Koutsogiannis) y el alargamiento de la barra lateral, que resultan de gran utilidad en la alineación de la columna medial como complemento. ${ }^{58}$

La tendencia de la doble osteotomía actualmente es más aceptada. ${ }^{57,58,59} \mathrm{La}$ artrodesis talonavicular y la artrodesis calcáneo-cuboidea cada vez se han dejado de realizar asociadas a tratamientos con tejidos blandos, debido a que el resultado es insuficiente para corregir la deformidad del pie plano adquirido del adulto.

\section{Artrorrisis}

La artrorrisis mediante endortesis deriva de la técnica de Grice,$^{60}$ utilizada hace años para la corrección del valgo de ta-

Figura 3: Avance de la inserción de tibial posterior (operación de Miller). 

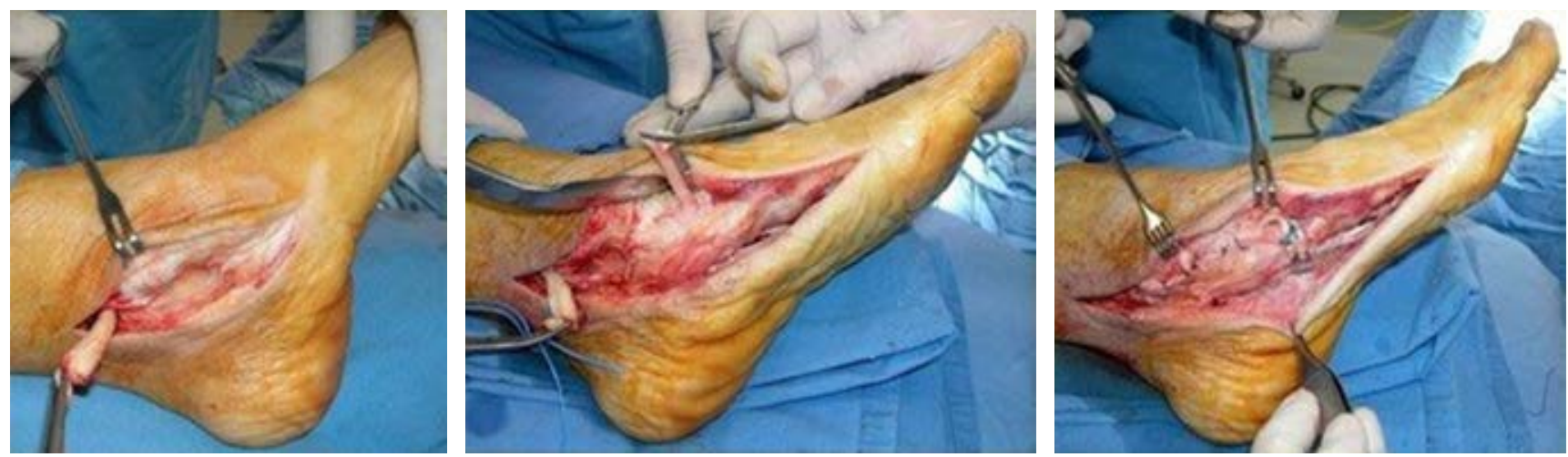

Figura 4: Rotura completa del tendón del tibial posterior. Anclaje al escafoides y tenoplastía con el cabo proximal.

lón, especialmente en pies paralíticos, muchos de ellos secuelas de poliomielitis. Posteriormente se utilizó la técnica modificada en pies planos infantiles de diferentes etiologías con buenos resultados. ${ }^{61}$ Desde hace cerca de 10 años, este procedimiento se ha empezado a utilizar en adultos, especialmente en algunos casos de pie plano por disfunción del tibial posterior, con la finalidad de corregir la desviación del retropié. .2,62 $^{2,2}$

En nuestra opinión, la indicación de una artrorrisis subastragalina mediante la colocación de un implante subtalar en el pie plano del adulto, con deformidad del retropié reductible, es fundamentalmente en el estadio 2 de Johnson y Strom, ${ }^{2}$ deformidad que va acompañada de supinación del antepié, también reductible, que se correspondería con el estadio II A1 de Bluman, Myerson y Title. $^{42}$

En algunos casos la indicación puede ampliarse cuando la supinación del antepié es irreductible, asociando una osteotomía tipo Cotton para descender el primer radio.

\section{Actuación complementaria sobre partes blandas}

La artrorrisis subastragalina se complementa habitualmente con una actuación quirúrgica sobre partes blandas, ${ }^{63}$ valorando que un correcto tratamiento sobre las mismas puede ayudar a optimizar el resultado del tratamiento.

Los gastrocnemios se encuentran acortados en muchas ocasiones, en nuestra experiencia en $80 \%$ de casos aproximadamente. Para valorar dicho acortamiento debe realizarse la maniobra de Silverskiold: flexionando dorsalmente el tobillo, con la rodilla en flexión y extensión y el talón en posición neutra, si la dorsiflexión no aumenta, el origen de la rigidez es por el tendón de Aquiles.

\section{Técnicas quirúrgicas}

Existen diferentes procedimientos para tratar el acortamiento de los gastrocnemios:

1. Alargamiento en «zeta» por cirugía abierta en el plano sagital o coronal.
2. Alargamiento mediante cirugía percutánea del tendón de Aquiles mediante dos o tres incisiones externas y una o dos internas.

3. Sección, por lo general parcial, del gastrocnemio medial debajo de la rodilla.

Barouk $^{64}$ y Delmi realizan la sección del gastrocnemio por debajo de la rodilla. Las técnicas propuestas por estos autores son las más utilizadas.

La reparación del tendón tibial posterior debe realizarse en relación con las características de la afectación del mismo. En casos de rupturas o desgarros parciales, la indicación es la tenosinovectomía abierta o cerrada con transferencias de refuerzo del tibial posterior al flexor común de los dedos. Cuando la ruptura es completa, se aconseja, si es posible, una sutura término-terminal (de cabo a cabo), en los casos en que hay mucha distancia entre ambos se utiliza el flexor propio del dedo gordo para suplir el tendón tibial posterior. ${ }^{25}$ (Ver apartado de Transferencias tendinosas).

La lesión del ligamento en hamaca o ligamento calcáneoescafoideo debe ser reparada en el acto operatorio. Para Cracchiolo ${ }^{25}$ la lesión del ligamento en hamaca constituye el inicio de las alteraciones que se irán presentando de manera progresiva en el pie plano del adulto por disfunción del tibial posterior.

Recordemos que la arquitectura del pie se mantiene por el encaje recíproco de los huesos entre sí y la función de los ligamentos. Los músculos colaboran con $10 \%$ de actividad (standing static), pero fundamentalmente haciendo variar la forma de la bóveda plantar (standing dinamic). De una manera gráfica si tenemos un pie de cadáver sobre una superficie plana y cortamos los tendones, no variará la forma del pie, excepto en el caso del tibial posterior, ya que éste tiene tres inserciones anterior, media y posterior que actúan, especialmente las dos últimas, como ligamentos formando parte del acetabulum pedis.

La afectación de estas inserciones tendinosas del tibial posterior puede determinar la ruptura del equilibrio del pie plano por disfunción a nivel de la articulación escafocuneana o cuneo-metatarsiana. (Lecciones básicas del aparato locomotor. A.Viladot Voegeli y cols. Springer). 
Técnica quirúrgica: Se comienza haciendo una valoración de la retracción del tendón de Aquiles realizando la maniobra de Silverskiold, manteniendo el talón en posición neutra. Si la retracción de los gastrocnemios es evidente se practica una tenotomía percutánea del tendón de Aquiles o una sección parcial del gastrocnemio medial por debajo de la rodilla.

Posteriormente se realiza abordaje del seno del tarso mediante una pequeña incisión premaleolar y submaleolar. ${ }^{65}$ Es importante en este momento quitar minuciosamente la grasa y cauterizar con la ayuda del bisturí eléctrico las paredes óseas del seno del tarso. Se trata de una zona con una gran inervación y conviene denervarla para prevenir dolor postoperatorio en la zona, lo que constituye la complicación más frecuente de esta técnica quirúrgica.

Maniobra de corrección: se desliza un instrumento romo (palanca de A. Viladot) ${ }^{65}$ en el seno del tarso por debajo del astrágalo de fuera hacia dentro. Se realiza un movimiento de supinación a nivel del retropié y de pronación en el antepié. Con ello conseguimos la corrección de la deformidad al colocar el astrágalo en su posición correcta.

Colocación del implante de prueba: se van colocando en el seno del tarso implantes de prueba de manera progresiva, de menor a mayor tamaño, hasta conseguir la corrección del valgo de talón, lo que se evalúa clínicamente.

Dejando colocado el implante de prueba que hemos elegido, se aborda el pie por su parte interna. Se valoran las lesiones del tendón tibial posterior y en función de ello se procede a la reparación quirúrgica con alguna de las técnicas expuestas anteriormente.

A continuación, se pone el implante definitivo de la endortesis en el seno del tarso (Figura 5). Posteriormente se procede al cierre de la herida y se coloca un vendaje de yeso almohadillado.

La deambulación sin carga se hará durante 15 días con la ayuda de bastones ingleses.

Posteriormente se revisa la herida operatoria, se retiran los puntos y se prescribe una bota tipo Walker que el paciente deberá llevar durante un mes, permitiendo la carga. Una vez retirada la bota se indican unas plantillas ortopédicas como medida de protección durante seis meses (Figura 6).

La técnica de la artrorrisis subastragalina debe ser equiparada con la osteotomía de medialización del calcáneo según la técnica de Koutsogiannis, ya que las indicaciones de ambos procedimientos para este estadio son muy semejantes.

En la osteotomía del calcáneo se realiza la corrección en un plano, mientras que en la artrorrisis la corrección se hace en los tres planos del espacio. El astrágalo es desplazado en la disfunción del tibial posterior hacia abajo, adelante y dentro, situándose al realizar la maniobra de corrección arriba, atrás y fuera, quedando estable en esta posición con una pequeña movilidad al colocar la endortesis.

El principal inconveniente de la artrorrisis subastragalina es el dolor residual postoperatorio a nivel del seno del tarso que puede presentarse. Ello puede, en gran medida, minimizarse con la extirpación de la grasa y la cauterización, como se ha comentado. Sin embargo, en nuestra serie de 37 pies en 35 pacientes intervenidos entre Enero de 2010 y Enero de $2015^{66}$ se tuvo que retirar la endortesis en 13 ocasiones, lo que supone 35\% del total. Es prudente esperar hasta el año de realizar la intervención para retirar la endortesis. Cabe señalar que no hubo pérdida de corrección ni clínica ni radiológica y que los dolores desaparecieron una vez realizada la extracción de la endortesis.

\section{Osteotomías del calcáneo}

En la deformidad del pie plano adquirido en el adulto, con frecuencia el tendón de Aquiles se acorta, ejerciendo un «momento de valgo» en el calcáneo, por lo que se produce un cambio de presión de la columna lateral a la columna medial con la consiguiente pérdida del arco interno. ${ }^{38}$

El tratamiento quirúrgico de la deformidad en el estadio II ha cambiado significativamente en los últimos 40 años. Los procedimientos de preservación articular tienen tendencia a realinear el retropié y a aumentar el tendón tibial posterior lesionado.

La transferencia del flexor largo de los dedos actualmente tiene prioridad sobre las artrodesis del retropié, que sólo se usan para tratar la deformidad en el estadio II-C de Bluman y Myerson o más avanzados. ${ }^{67}$ Las múltiples publicaciones y la evidencia muestran claramente que la transferencia del flexor por sí solo no funciona. ${ }^{68}$ Por lo tanto, la cirugía correctiva que involucra una osteotomía del calcáneo es absolutamente necesaria para apoyar la transferencia del flexor y la reparación de los tejidos blandos.
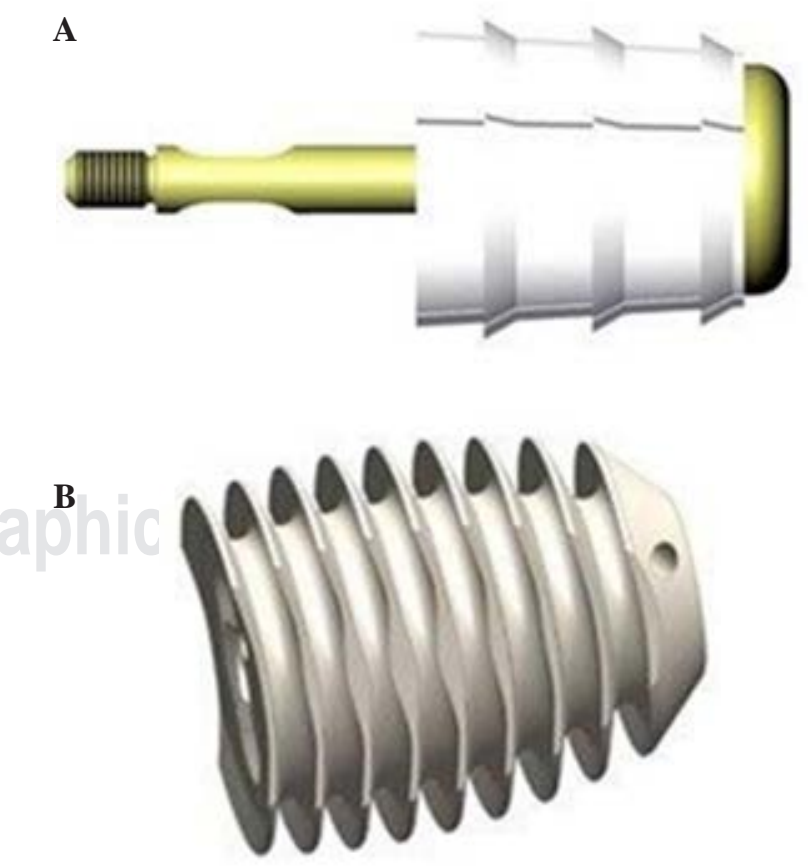

Figura 5: A) Endortesis Kalix. B) Endortesis Pit Stop. 
Los procedimientos correctores que están indicados en este estadio son:

\section{Osteotomía medializante de Koutsogiannis}

La primera osteotomía de medialización para el tratamiento de la disfunción del tibial posterior se le acredita a Koutsogiannis en 1971, quien interviene a 34 pacientes. ${ }^{69,70,71,72}$ Desde entonces, numerosos autores, entre ellos Mann, ${ }^{73}$ Myerson, ${ }^{74}$ Pomeroy y Manoli, ${ }^{75}$ Fayazi, ${ }^{76}$ Wacker, ${ }^{77}$ Guyton, ${ }^{78}$ Sammarco y Hockenbury ${ }^{79}$ han informado resultados favorables después de realizar una osteotomía de medialización con transferencia de tendones o reparación de ligamento en hamaca para el tratamiento del estadio II.

La osteotomía de medialización es aceptada actualmente como un procedimiento específico para el estadio II por reducir las tensiones de contacto en la articulación tibioastragalina. ${ }^{80}$

Los estudios experimentales en cadáver indican aumentos en la presión máxima sobre la parte lateral del talón. ${ }^{81}$ Una traslación de $10 \mathrm{~mm}$ disminuye sustancialmente la carga sobre el primer metatarsiano, la carga del arco medial y el momento en la articulación astrágalo escafoidea.

La osteotomía de medialización también aumenta la carga en el borde lateral, corrigiendo así el cambio en la distribución de fuerzas que ocurre ${ }^{82}$ al permitir que el tendón de Aquiles actúe en forma armónica con el tendón tibial posterior en sinergia, ayudando a supinar y estabilizar el antepié como un brazo de palanca rígido durante la elevación y propulsión del talón. ${ }^{83}$ Brodsky reportó mejoría significativa en el análisis de la marcha en el postoperatorio en términos de cadencia, longitud de zancada y despegue del pie $^{84}$ en pacientes en los que se realizó una osteotomía junto con la transferencia del flexor.

Se ha debatido el papel de la fascia plantar después de realizar una osteotomía, demostrándose que no se presenta un aumento de tensión en la fascia plantar. En realidad, la fascia plantar disminuye su tensión en $2.7 \mathrm{~mm} .{ }^{85}$

Myerson reportó 120 pacientes en los que se realizó una osteotomía de Koutsogiannis, transferencia del flexor del primer dedo y reparación de ligamento en hamaca con una gran mejoría en el dolor y la función en $90 \% ;{ }^{74}$ sin embargo, la medición radiográfica del arco longitudinal interno varío enormemente de un paciente a otro a pesar del buen resultado clínico. Refiere además que las mejorías radiográficas se pueden perder con el tiempo. ${ }^{86}$

Por último, aunque puede haber una mejora radiográfica en la alineación y la altura del arco longitudinal medial, la apariencia externa a veces sólo puede modificarse en un pequeño número de pacientes. ${ }^{78}$

Las contraindicaciones más comunes de la osteotomía incluyen la rigidez y artritis degenerativas del retropié. Las complicaciones más frecuentes son la irritación de los tendones peroneos y la neuritis sural. La seudoartrosis es rara porque hay una excelente vascularización. El
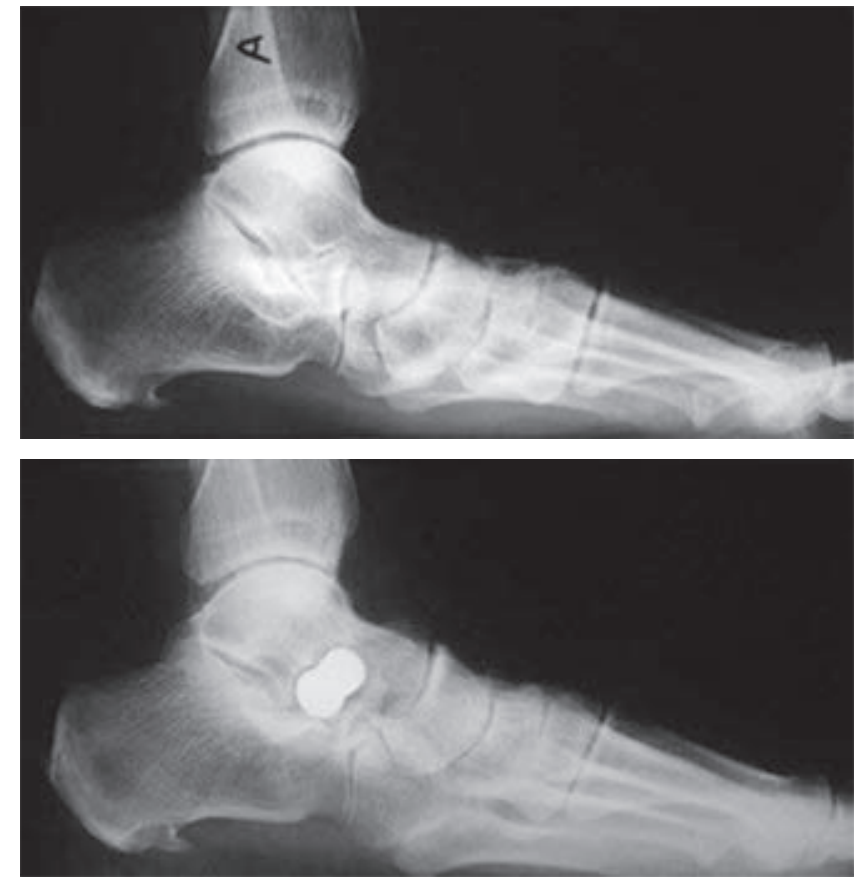

Figura 6: Disfunción del tibial posterior E-II. Endortesis Kalix. Observar la corrección de la línea de Feiss.

dolor producido por el tornillo desaparece cuando se retira. Se han reportado fístulas arteriovenosas y parálisis del nervio tibial. ${ }^{87,88,89}$

Técnica quirúrgica: la incisión se inicia por debajo del maléolo lateral en un ángulo aproximado de 45 grados, evitando el nervio sural y sus ramas así como los tendones peroneos. La disección continúa hasta el hueso, los separadores de Hohmann se colocan en posición dorsal y plantar alrededor del hueso para proteger las estructuras y los tejidos blandos. La osteotomía se realiza controlando la profundidad de la sierra, asegurándose de no penetrar en la cortical medial. Se puede usar un osteótomo para completar el corte de la cortical medial y un separador laminar para abrir la osteotomía y estirar el periostio medial permitiendo un mayor desplazamiento. Con el pie en flexión plantar la osteotomía se fija temporalmente con agujas de Kirschner. El calcáneo se desplaza aproximadamente $1 \mathrm{~cm}$ y luego se verifica con imágenes radiográficas axiales. La fijación se realiza generalmente con un tornillo canulado de $6.5 \mathrm{~mm}$ o una placa en «escalera» lateral (Figura 7).

En 2016, Saxena y colaboradores analizaron a 31 pacientes en quienes se realizó una osteotomía de medialización, 17 fijadas con un solo tornillo y 14 con una placa de bloqueo lateral, tres pacientes requirieron la extracción de la placa en comparación con uno en el que se implantó un tornillo. No se observaron diferencias significativas con las puntuaciones AOFAS postoperatorias y no se produjeron retardos de consolidación, desplazamientos o infecciones.$^{90}$ Kendal y Ball en 2018 compararon 50 procedimientos abiertos con 32 por mínima incisión, se logró un desplazamiento medio del 
calcáneo de $8 \mathrm{~mm}$ para el grupo MIS y $8.33 \mathrm{~mm}$ para el grupo abierto. Hubo significativamente menos complicaciones de la herida en el grupo MIS (6.25\%) en comparación con el grupo abierto (28\%). Las complicaciones del nervio sural MIS también fueron significativamente menores ${ }^{91}$ Charlie y Jowett $^{92}$ y Kheir y Borse ${ }^{93}$ también muestran tasas de 100\% sin complicaciones de heridas, consolidación o lesión nerviosa. Por lo tanto, la osteotomía calcánea mediante el procedimiento MIS ofrece una alternativa en comparación con la cirugía abierta.

\section{Alargamiento de la columna lateral (Evans)}

Los orígenes de este procedimiento provienen de un error cometido por un cirujano durante la corrección de un pie zambo. En su artículo original, Dillwyn Evans en 1961 publicó la técnica para corrección de recidivas de pie zambo. ${ }^{94}$

Una parte de la cirugía consistió en realizar una artrodesis calcáneo cuboidea con acortamiento del calcáneo. Sin embargo, en dos fracasos notó una sobrecorrección secundaria a una resección ósea excesiva que causó un borde medial convexo. Después de intentar correcciones con osteotomías calcáneas, finalmente concluyó que la columna lateral acortada había producido una rotación lateral del escafoides sobre el astrágalo que no podía corregirse fácilmente mediante un desplazamiento mecánico del talón. Llegó a la conclusión de que la columna lateral tenía que alargarse para medializar el talón, reducir la convexidad del borde medial, reducir el escafoides sobre el astrágalo y restaurar el equino natural del pie.
Posteriormente en el artículo de Evans de 1975 quedaba claro que quería preservar la articulación calcáneo cuboidea. ${ }^{95}$ Realizó este procedimiento en 56 pies describiendo una osteotomía de $1.5 \mathrm{~cm}$ proximal en forma paralela a la articulación. La osteotomía se fijó con hueso cortical tibial ipsilateral y el paciente fue inmovilizado con aparato de yeso durante cuatro meses.

Mosca y otros autores posteriormente modificaron el procedimiento de Evans con la premisa de que el centro de rotación para la corrección está cerca del centro de la cabeza del astrágalo y no sólo en la cortical medial del calcáneo; por lo tanto, la osteotomía no es una osteotomía simple de distracción o de cuña. La dirección de la osteotomía se modificó comenzando $1.5 \mathrm{~cm}$ proximal/lateral a la articulación y se dirigió distal/medial de forma oblicua. Recomendaron un injerto de cresta ilíaca tricortical con forma trapezoidal para llenar el espacio restante..$^{96}$

La corrección anatómica del alargamiento de la columna lateral puede ser muy eficaz. Sangeorzan ${ }^{59}$ la comparó en un estudio radiográfico en el preoperatorio y postoperatorio, el cual mostró que el ángulo astrágalo calcáneo lateral mejoró 6.4 grados, la cobertura astrágalo escafoidea mejoró 26 grados y la inclinación del calcáneo en 10.8 grados. Dumontier ${ }^{97}$ verificó en un modelo de pie plano en cadáver aún más los efectos posicionales del procedimiento de Evans. Observó cómo la estructura de la cabeza del astrágalo afectaba el movimiento del escafoides a su alrededor. La cabeza es más ancha en dirección medial-lateral que en dirección dorso-plantar.

A medida que se alarga la columna lateral, hay un movimiento medial del antepié en la articulación transversa.
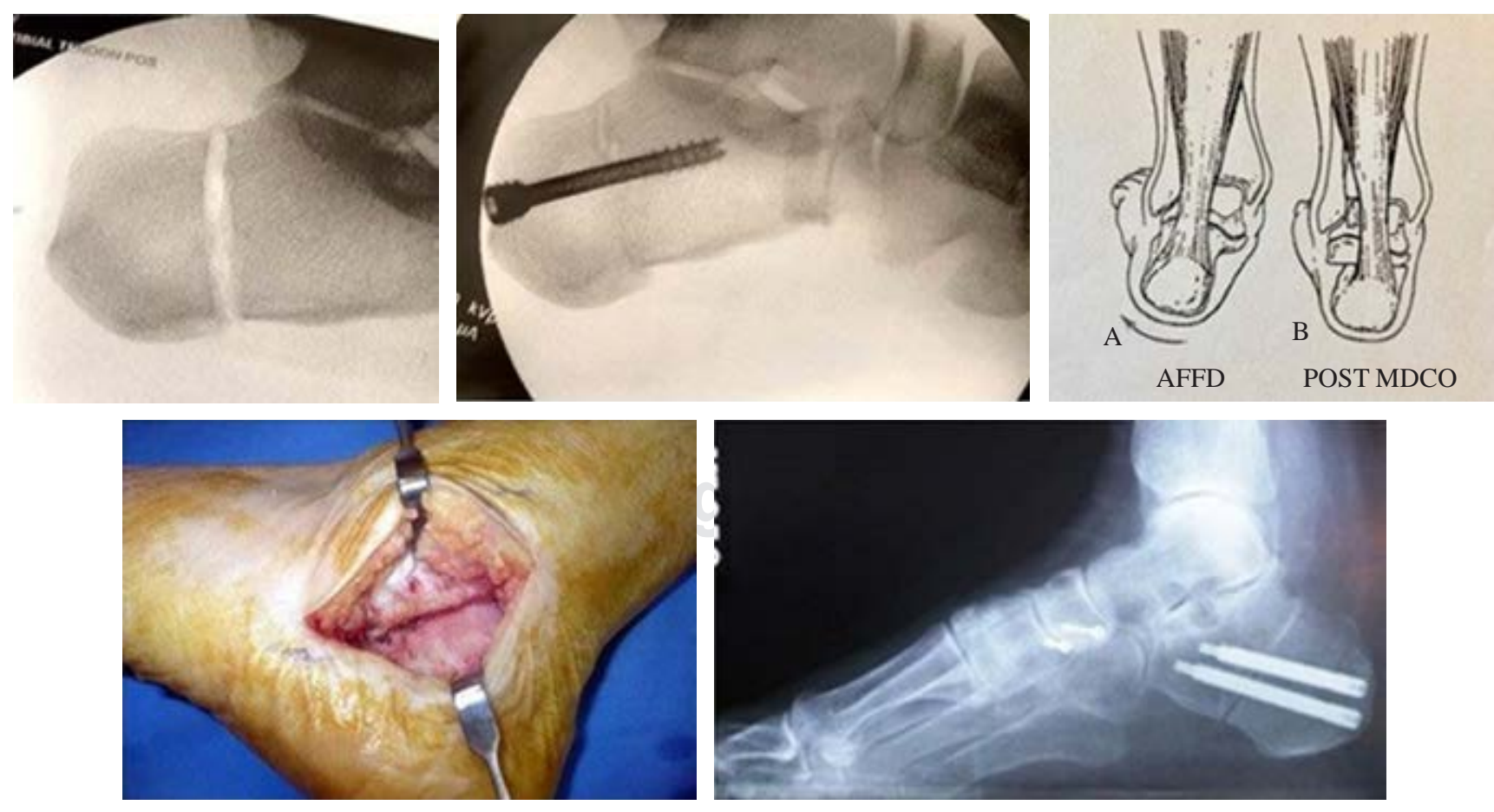

Figura 7: Osteotomía de Koutsogiannis. 


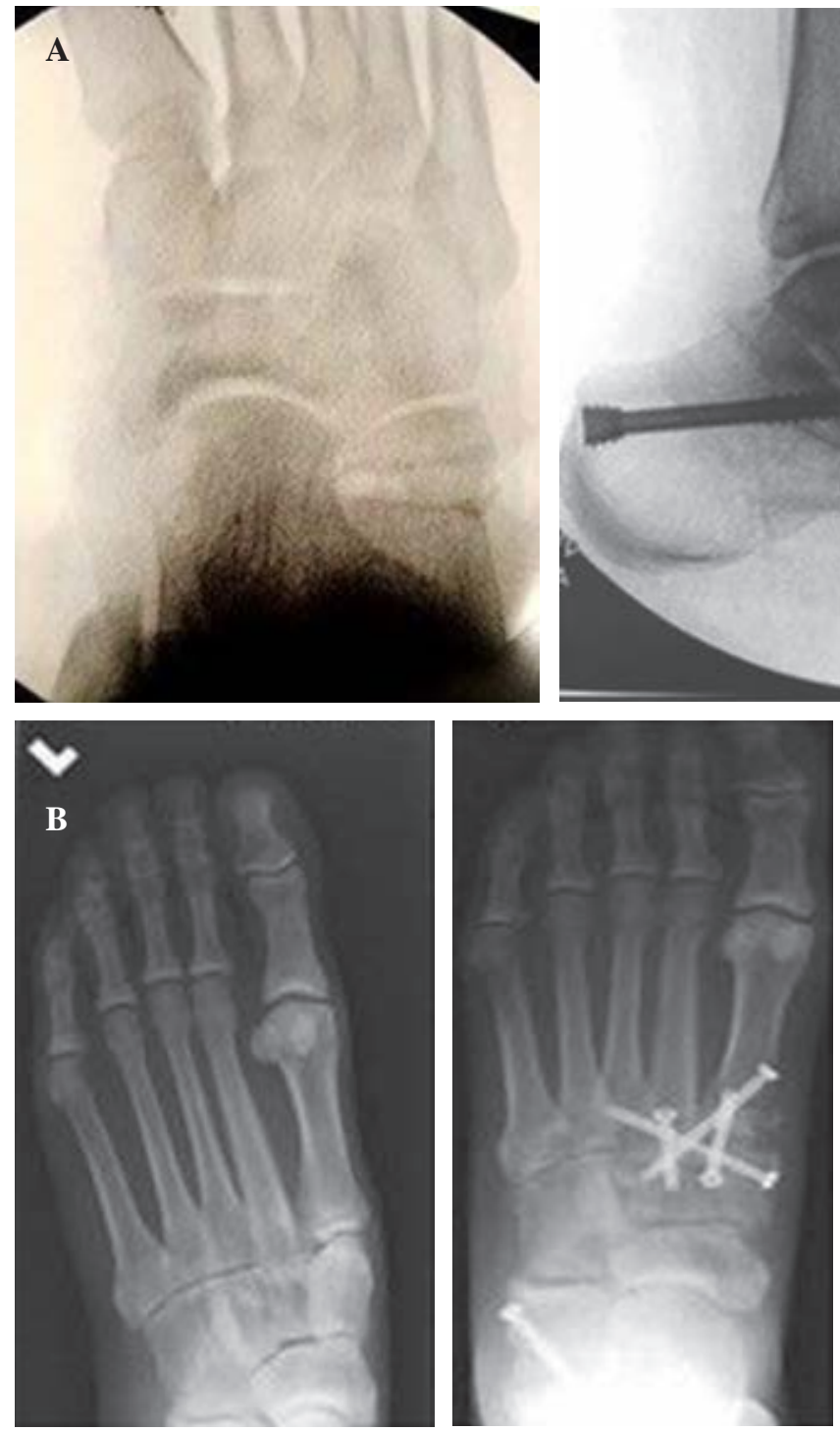

Además, el escafoides se mueve ligeramente hacia la posición plantar, lo que resulta en aducción y flexión plantar del antepié aumentando el arco longitudinal interno. El escafoides rota 18.6 grados de aducción, 2.6 grados de pronación, 3.4 grados de flexión plantar. $5.6 \mathrm{~mm}$ medial, $0.4 \mathrm{~mm}$ posterior y $1.8 \mathrm{~mm}$ plantar. El cuboides gira 24.2 grados de aducción, 13.9 grados de pronación. 1.9 grados de flexión plantar, $9.4 \mathrm{~mm}$ medial, $2.6 \mathrm{~mm}$ distal y $1.5 \mathrm{~mm}$ plantar. El calcáneo no se coloca en varo en relación con el astrágalo o la tibia, lo que sugiere que es la corrección del mediopié y el antepié lo que da la apariencia de calcáneo varo. ${ }^{97}$

Técnica quirúrgica: se realiza una incisión de 5-7 cm de longitud, comenzando en la articulación calcáneo cuboidea y extendiéndose proximalmente en línea con el borde superior del calcáneo. La cápsula articular no se abre. Se introduce un retractor para proteger los tejidos blandos y dar exposición. La disección subperióstica se realiza lo suficiente para permitir el uso de una sierra u osteótomo de 1 a $1.3 \mathrm{~cm}$ proximales a la articulación, se realiza la osteotomía, ya sea

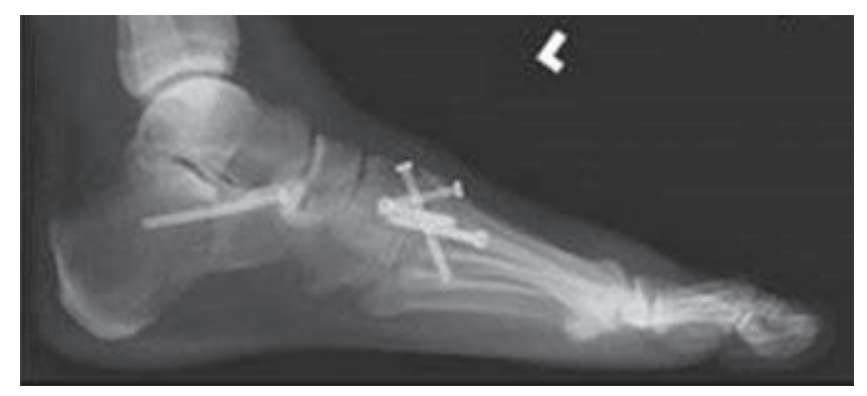

Figura 8:

Osteotomía de Evans, A) asociada a osteotomía de la primera cuña. B) Asociada a artrodesis de Lisfranc.

transversal recta u oblicua ligeramente distal. Se introduce un separador laminar para abrir la osteotomía y se llena con una cuña de injerto óseo, autoinjerto o aloinjerto, según la preferencia del cirujano. Se realiza la fijación con una placa, tornillo o grapa (Figura 8). Se inmoviliza con aparato de yeso suropodálico o se lo coloca en una bota tipo Walker, con apoyo diferido durante seis semanas, luego se progresa según el seguimiento clínico y radiográfico.

$\mathrm{Hix}^{98}$ recomienda una osteotomía de alargamiento en $\mathrm{Z}$. Guha ${ }^{99}$ utiliza un corte vertical distal de $10 \mathrm{~mm}$ proximal a la articulación calcáneo cuboidea a través de la mitad dorsal del proceso anterior conectado con un corte horizontal de espesor completo a través del calcáneo y finalmente completado por un corte plantar vertical al nivel del tubérculo peroneo. Aunque el número de pacientes es pequeño, los resultados son buenos. Técnicamente es más exigente, pero debe considerarse como una opción adicional.

En casi todas las publicaciones, el tamaño del injerto fluctúa entre 6 y $12 \mathrm{~mm}$. Sin embargo, los estudios cada- 
véricos muestran que la presión en la articulación calcáneo cuboidea comienza a aumentar cuando el injerto es mayor de $8 \mathrm{~mm}$ y se incrementa significativamente con respecto a un pie normal con injertos de más de $10 \mathrm{~mm}$ de ancho. Se recomienda que si es necesaria una corrección mayor, combinar la osteotomía con procedimientos complementarios. Hintermann ${ }^{100}$ ha informado de una incidencia de lesión del nervio sural de $11 \%$.

El tendón peroneo largo puede estar comprometido si la osteotomía se realiza a menos de $10 \mathrm{~mm}$ de la articulación. La faceta media de la articulación subastragalina puede estar comprometida si la osteotomía se realiza a $1.5 \mathrm{~cm}$ proximal a la articulación. Bussewitz demostró que si la osteotomía se hace a $1.3 \mathrm{~cm}$ proximales y en ángulo oblicuo distal (Mosca), se reduce la lesión del sustentaculum tali. La sobrecorrección es rara y se asocia principalmente con pies planos espásticos. La corrección insuficiente también es rara y se observa principalmente en casos de coaliciones astrágalo calcáneas.

El alargamiento del tendón de Aquiles también es importante para evitar la corrección insuficiente y la recurrencia. La literatura actual apoya el Evans clásico sobre artrodesis calcáneo cuboidea debido a las mayores tasas de complicaciones.

La osteotomía de Evans tiene un efecto tridimensional que la convierte en un componente esencial en el tratamiento quirúrgico del pie plano valgo flexible estadio II. Las complicaciones son de baja incidencia y están relacionadas con la selección de los pacientes, el abordaje quirúrgico y la corrección de la geometría del pie. La falta de unión es infrecuente y varía de 1.4 a 5.26\%. ${ }^{101,102,103,104}$ La subluxación dorsal de la tuberosidad anterior del calcáneo puede ocurrir con frecuencia, pero a menudo se autocorrige. ${ }^{105}$

La sobrecarga de la columna lateral puede ocurrir si la magnitud de la corrección es demasiado grande. La artrosis calcáneo cuboidea es de muy baja incidencia 11\% según Thomas y no siempre es atribuible a la osteotomía.

Otras complicaciones que se presentan con mayor frecuencia son: la irritación del tendón peroneo o neuritis sural, la no unión es extremadamente rara debido al gran aporte sanguíneo. El dolor sobre la cabeza del tornillo es común y puede requerir la extracción del mismo después de la consolidación.

También se debe tener cuidado para evitar perforar la cortical medial para no dañar las estructuras neurovasculares mediales. Se han informado casos esporádicos de lesiones en estructuras mediales e igualmente se han observado fístulas arteriovenosas tibiales posteriores, parálisis del nervio tibial y del nervio plantar lateral. ${ }^{106}$

Las contraindicaciones más comunes incluyen deformidad rígida y artritis degenerativa severa del retropié.

\section{Osteotomía doble del calcáneo}

Esto incluye una osteotomía de medialización con un alargamiento de la columna lateral. Estas osteotomías dobles corrigen dos aspectos principales del pie plano adquirido. Introducido por primera vez por Frankel en 1995, la osteotomía corrige el valgo del retropié y el alargamiento de la columna lateral, es decir, corrige la abducción del antepié y aumenta la altura del arco. Esta doble corrección reduce las presiones en cada osteotomía individual, lo que resulta en una corrección más anatómica de la deformidad y una disminución de la recurrencia. . $9,75,106$

Se ha demostrado que las osteotomías de calcáneo son procedimientos extremadamente poderosos en la corrección de la disfunción del tibial posterior. La corrección de la deformidad en ocasiones es insuficiente, por lo tanto, ambos procedimientos se usan complementariamente y son necesarios para lograr una corrección satisfactoria a largo plazo.

\section{Osteotomía en «Z» de calcáneo (Malerba)}

Esta osteotomía comienza proximalmente con un corte posterior a la faceta articular posterior, luego se extiende de manera distal y por último se realiza un corte plantar distal. La oblicuidad de los cortes superiores e inferiores proporciona una aposición hueso sobre hueso para la consolidación. Se puede colocar una cuña en el corte inferior distal de manera similar a la osteotomía de Evans que permita el alargamiento de la columna lateral así como la traslación medial de la parte posterior del calcáneo. Esto combina un desplazamiento me-

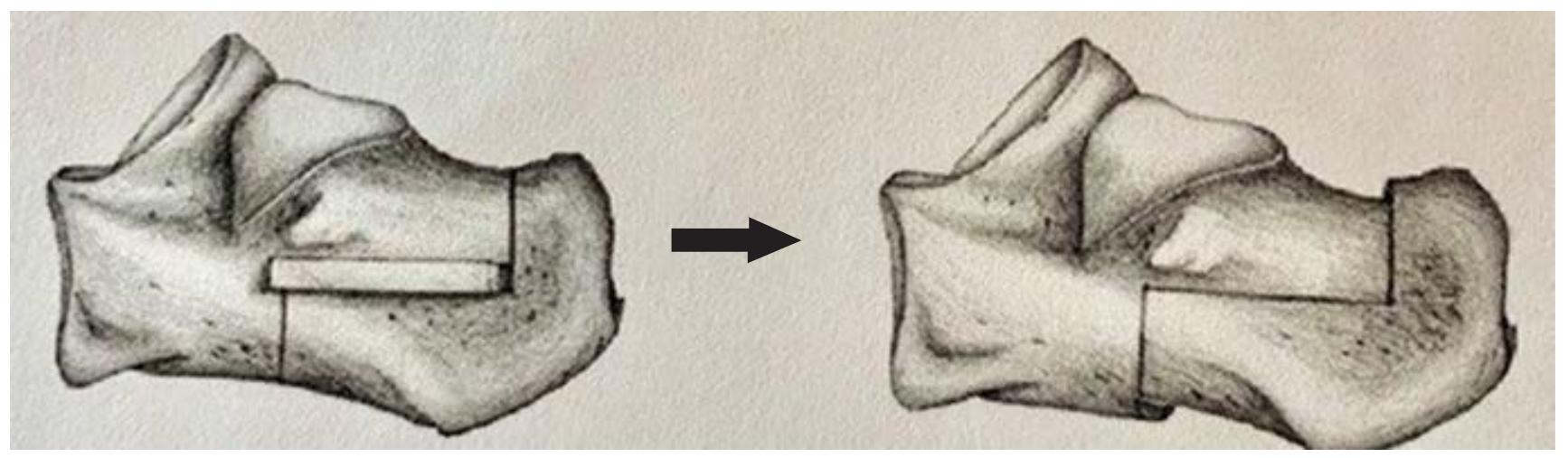

Figura 9: Esquema de la osteotomía en Z. 
dial de la tuberosidad calcánea y el alargamiento de la columna lateral a través de un abordaje extensible (Figura 9). ${ }^{100} \mathrm{La}$ osteotomía permite que la tuberosidad del calcáneo se desplace medial o lateralmente. La eliminación de una cuña de base lateral se suma a la corrección del varo del talón e incorpora una gran superficie ósea y su estabilidad fomenta la consolidación ósea temprana. Se estabiliza con grapas o tornillos y permite soportar peso a las seis semanas.

\section{Triple artrodesis}

La evolución progresiva de la deformidad va a conllevar la aparición de una deformidad rígida producida por la artrosis, que sucesivamente ha ido desarrollándose en el tiempo, evolucionando finalmente hacia un pie plano rígido doloroso (estadio III de Myerson y Haddad). ${ }^{107}$

A largo plazo es frecuente la aparición de cambios degenerativos en articulaciones vecinas tanto en tobillo como en el tarso medio, tan es así que este suceso no llega a considerarse sino una consecuencia que se espera de dicho procedimiento y no una complicación o fracaso. ${ }^{108}$

El tratamiento de elección para este estadio III es la fijación completa de la articulación de Chopart o triple artrodesis del tarso posterior. ${ }^{73,109,110,111}$

Existe una diferenciación semántica que puede conducir a error por incluirse dentro del mismo nombre. Entre los cirujanos europeos se conoce como doble artrodesis por considerar que la articulación calcáneo cuboidea y astrágalo escafoidea constituyen una única articulación. Para los cirujanos anglosajones la intervención se denomina triple artrodesis, ya que se interpreta que cada una de estas articulaciones trabaja como un conjunto desde el punto de vista funcional, pero desde el punto de vista anatómico hay que considerarlas tres articulaciones aisladas. ${ }^{111,112} \mathrm{La}$ finalidad de la intervención es obtener un pie plantígrado, indoloro y que mejore la adaptabilidad funcional del paciente permitiéndole una actividad mejor y el uso de un calzado normal. ${ }^{113}$

Esta técnica para este estadio ha demostrado ser fiable y reproducible, obteniéndose una buena corrección de la deformidad así como buenos resultados clínicos satisfactorios. Es un procedimiento altamente demandante y no exento de complicaciones.

En el postoperatorio temprano pueden presentarse con cierta frecuencia problemas de cicatrización de las heridas así como defectos de consolidación o consolidación viciosa.

Indicación: estadio III-A o III-B y opcional en el IV (Myerson. Haddad) ${ }^{107}$ donde exista un valgo del retropié rígido con o sin aducción metatarsal e inestabilidad sagital. ${ }^{114,115,116}$

Como contraindicación habrá que tener en consideración una infección activa, inmunodeficiencia, malnutrición o enfermedad vascular periférica.

La presencia de degeneración articular a nivel tibioastragalino nos marcará la necesidad de intervención más allá de la que implique el retropié y mediopié. ${ }^{117}$ La proyección de
Saltzman ${ }^{115}$ aportará mayor información sobre la alineación del retropié.

Técnica quirúrgica: la elección de la incisión depende de la técnica a elegir. Tradicionalmente se ha empleado el doble abordaje, aunque existen autores que emplean el abordaje medial único.

Se efectúa abordaje en el seno del tarso, un dedo por debajo del maléolo peroneo hasta la base del segundo metatarsiano (Olier); la disección se practica a través del seno del tarso, se desperiostiza el calcáneo y se reseca el tejido graso del seno tarsal. Se diseca el músculo pedio y se retrae en sentido distal. Los músculos peroneos se retraen hacia atrás para exponer la articulación subastragalina y hacer una artrotomía de las articulaciones astrágalo escafoidea, calcáneo cuboidea y subastragalina liberando dichas estructuras, con especial cuidado de no despegar en exceso el periostio y la cápsula del cuello astragalino para no interferir con la vascularización. Se efectúa la resección de las superficies articulares o se realizan cuñas de resección correctoras según requiera.

El abordaje lateral se realiza a través de una incisión partiendo de la punta del maléolo lateral hasta la base del cuarto metatarsiano. Se deben proteger las ramas comunicantes del nervio sural con el peroneo superficial (rama dorso lateral), identificaremos el origen del músculo pedio y lo desinsertaremos proximalmente para rechazarlo a distal. La vaina de los peroneos se desinserta con un periostótomo y se rechaza distal para una correcta visualización de la articulación subastragalina posterior.

Tras dividir el ligamento interóseo, conseguiremos un mejor acceso a las superficies articulares, que será óptimo con la colocación de un distractor laminar o un separador de Hintermann.

El acceso a la articulación calcáneo cuboidea se conseguirá tras la retracción del músculo pedio. Resulta de gran ayuda la disección del ligamento bifurcado para una mejor visión. ${ }^{118}$

El abordaje medial se realiza partiendo del distal al maléolo medial en dirección a la articulación, astrágalo escafoidea superando el nivel de ésta $1 \mathrm{~cm}$ distal. Buscaremos el intervalo entre el tibial anterior y posterior, evitando lesionar la vena safena y su nervio acompañante.

Para una exposición mayor, seguiremos los mismos principios que en el abordaje lateral, con la disección de la cápsula articular y el empleo de distractores articulares. Comenzando por la articulación subastragalina disecaremos consecutivamente la calcáneo cuboidea y la astrágalo escafoidea eliminando el cartílago remanente en estas articulaciones y dejando superficies de hueso esponjoso sangrante. ${ }^{119}$

El empleo de injerto óseo puede resultar útil, aunque no es imperativo. La reducción de las articulaciones seguirá un orden. Comenzaremos por la articulación astrágalo escafoidea seguida de la articulación subastragalina, buscando un pie plantígrado con una alineación en valgo de $5^{\circ}$ de retropié. 
En un plano de larga evolución no es infrecuente el colapso de la cabeza astragalina requiriendo de una pequeña cuña de base medial que permita una adecuada corrección de la abducción del mediopié. Conseguiremos la reducción pronando, aduciendo y flexionando a plantar el antepié mientras mantenemos la posición del astrágalo. Una vez conseguida la reducción deseada, realizaremos una estabilización temporal con agujas de Kirschner; tras comprobar la idoneidad de la corrección y posicionamiento de las agujas, la osteosíntesis definitiva es secuencial, aunque en este caso comenzaremos con la estabilización de la subastragalina, seguida de la astrágalo escafoidea y calcáneo cuboidea.

La triple artrodesis a menudo precisa de gestos accesorios como el alargamiento del gastrocnemio medial, en último lugar ${ }^{120,121}$ (Figura 10), tenotomía de alargamiento del tendón de Aquiles u osteotomías plantarizantes del primer radio (Cotton) en el caso de una supinación residual del antepié. Con menos frecuencia podemos encontrarnos con la necesidad de realizar otros gestos sobre tendones peroneos o articulaciones distales a astrágalo escafoidea así como reconstrucciones de ligamento deltoideo o procedimientos sobre la articulación tibioastragalina dependiendo de su estado y balance de partes blandas.

Ruiz Nasarre, Álvarez Goenaga y Viladot $\mathrm{R}^{65}$ publican en 2013 en la Revista del Pie y Tobillo de España un procedimiento de doble artrodesis subastragalina y astrágalo escafoidea por un único abordaje medial.

Refiere que constituye una excelente alternativa a la triple artrodesis clásica por doble abordaje porque permite una corrección satisfactoria del pie plano valgo severo, disminu- ye la complejidad quirúrgica, preserva la articulación calcáneo cuboidea y muestra una baja tasa de complicaciones y un alto grado de satisfacción de los pacientes.

En todos los casos realizaron un alargamiento percutáneo del tendón de Aquiles y la estabilización se consiguió mediante osteosíntesis con un tornillo de $7.5 \mathrm{~mm}$ de diámetro en la articulación subastragalina posterior y dos tornillos de $5.5 \mathrm{~mm}$ en la articulación astrágalo escafoidea.

En la mayoría de los trabajos publicados sobre triple artrodesis la fijación más utilizada es mediante tornillos de esponjosa con la que se han obtenido buenos resultados. Sin embargo, Odgaard y Schwetlick utilizaron grapas como método de fijación interna y no reportaron ningún caso de seudoartrosis, poniendo de manifiesto que no existen grandes diferencias al comparar los resultados obtenidos entre la osteosíntesis con tornillos y con grapas.

\section{Artrodesis tibio astrágalo calcánea}

El desarrollo progresivo en el tiempo de la disfunción supone un tendón degenerado o roto que evoluciona hacia una deformidad que termina afectando prácticamente a todo el pie y se corresponde con el estadio IV. ${ }^{122}$

La caída del arco longitudinal en este estadio es irreductible, el retropié está en valgo, con insuficiencia del ligamento medial y colapso del astrágalo, con cambios degenerativos artrósicos a nivel de las articulaciones subastragalina, astragaloescafoidea y tibioastragalina.

La deformidad puede ser flexible (estadio IV-A) o rígida (estadio IV-B), según el momento de la evolución y la existencia o no de artrosis.
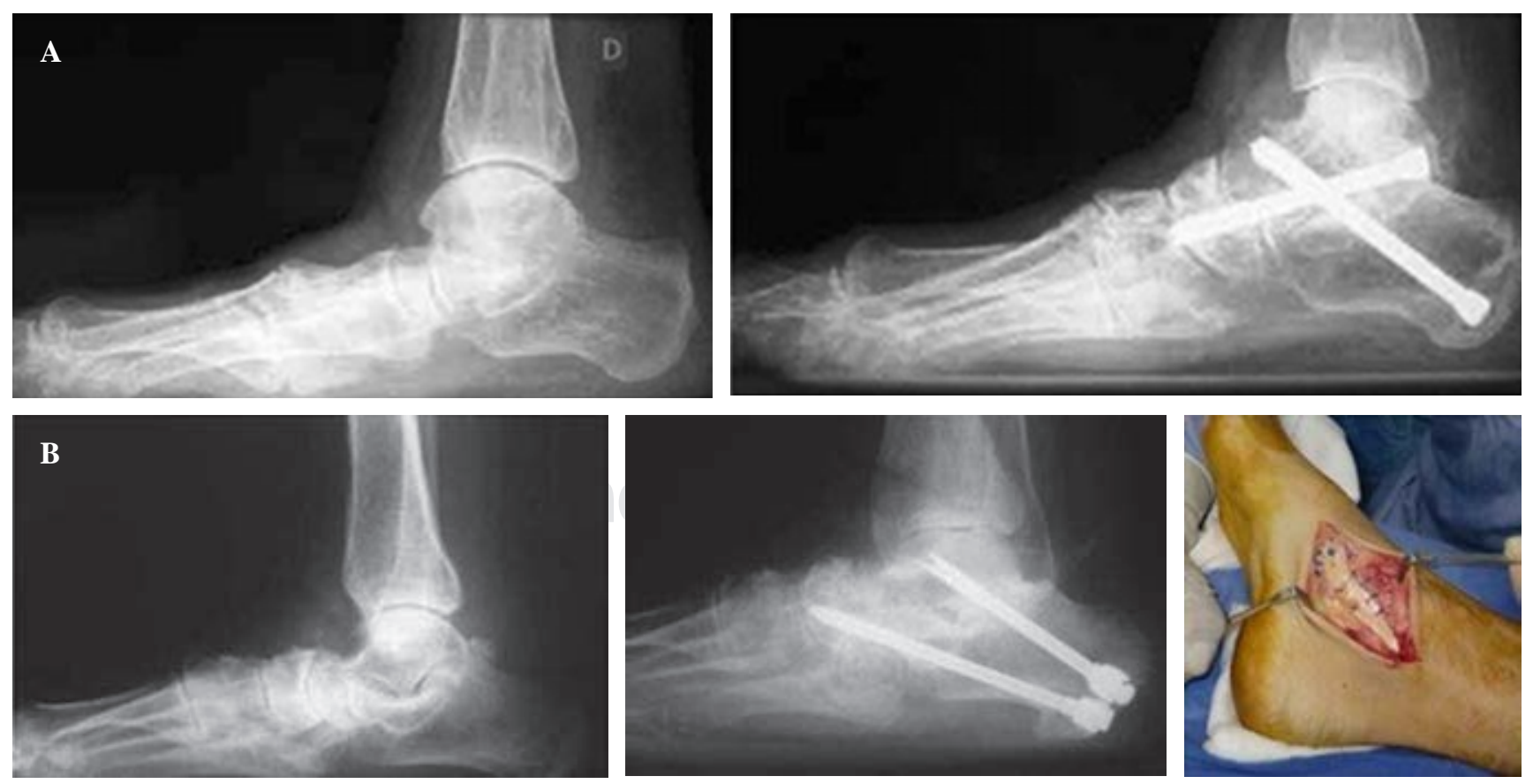

Figura 10: Triple artrodesis, A) retropié rígido en valgo, con injerto óseo autólogo. B) Artrosis subastragalina. Inestabilidad medial refuerzo con tendón tibial posterior. 
Los criterios para evaluar si la deformidad es elástica o no están en función, si el tendón es o no funcional y si la articulación subastragalina conserva o no su movilidad. ${ }^{123}$

$\mathrm{Al}$ ser un proceso evolutivo, en estadios previos (II y III) ya se empieza a asociar progresivamente, la rigidez del tríceps sural (gastrocnemio y/o sóleo), el acortamiento del tendón de Aquiles y la limitación de la flexión dorsal e inversión del pie.

A medida que el tendón tibial posterior pierde su función, el arco longitudinal medial se colapsa (estadio IV), lo que provoca una rotación interna relativa de la tibia y del astrágalo. ${ }^{37}$ Hay eversión de la articulación subastragalina que fuerza el talón en valgo y desviación de la articulación astragaloescafoidea, llegando a ser ineficaz la función del ligamento deltoideo.

A medida que la deformidad empeora, el peroné distal entra en contacto con el lateral del calcáneo, provocando dolor permanente en la parte posterior del pie.

En ambos casos IV-A y IV-B, el retropié se orienta en valgo así como la articulación tibiotalar. En el estadio IV-B el astrágalo tiende a luxarse fuera de la mortaja por la situación en valgo del calcáneo y por la incompetencia por laxitud o rotura del ligamento deltoideo, produciéndose una inestabilidad peritalar. El antepié se aduce y la articulación metatarso falángica se dispone en valgo, presentando una deformidad típica de hallux valgus.

A la exploración física, la debilidad del tendón se objetiva por la disminución de la fuerza inversora del retropié, ya sea con el paciente sentado en la camilla o de pie. Hay en mayor o menor grado disminución del tono muscular, que se evidencia con el paciente en decúbito dorsal por la posición espontánea del pie en menor inversión y supinación que en el lado contralateral.

La falta de homogeneidad muscular es indicativa de rotura parcial o tendinopatía crónica.

Para confirmar el diagnóstico, se debe hacer una exploración clínica mediante pruebas funcionales ${ }^{124}$ que nos confirmen el diagnóstico: «demasiados dedos», signo de Rodríguez Fonseca y «elevación del primer metatarsiano», etc., anteriormente referidas.

Los pacientes con disfunción del tibial posterior en estadio IV son incapaces de ponerse de puntillas con un único talón sin apoyo ipsilateral, es decir, no pueden pasar de la posición bipodal a monopodal.

Como exploración de imagen complementaria, las radiografías simples en carga son de gran utilidad para evaluar el grado de deformidad. La disrupción de la línea de Meary, el retropié en valgo, la alineación y desplazamiento del astrágalo, la orientación del calcáneo la articulación astrágalo escafoidea descubierta y la aducción del antepié son datos radiográficos que nos ayudarán a valorar el grado de deformidad. De igual modo serán de gran utilidad para confirmar la presencia o no de cambios degenerativos artrósicos en las articulaciones subastragalina, articulación de Chopart y tibioastragalina.

No obstante, existen diferentes técnicas de imagen (RM Conti score, ${ }^{125}$ TAC, ${ }^{126}$ ecografía y PET-TAC) para evaluar el estado del tendón y su vaina, así como la laceración del ligamento medial y la deformidad del pie.
Tratamiento quirúrgico: en el estadio IV se produce una deformidad en valgo del retropié e inestabilidad periastragalina que resulta de la degeneración progresiva del tendón tibial posterior y la rotura del ligamento deltoideo que van a condicionar o no una luxación en valgo del astrágalo dentro de la mortaja tibioastragalina.

En el estadio IV-A, la deformidad es relativamente elástica, por lo que se puede realinear el valgo del talón y reparar el ligamento deltoideo, bien directamente o mediante un injerto propio o de banco, bien se opte por una osteotomía o una triple artrodesis.

En pacientes con una deformidad de tobillo flexible sin artrosis tibioastragalina (estadio IV-A) pueden indicarse procedimientos que preserven la articulación. ${ }^{118}$

En ocasiones la reconstrucción mínimamente invasiva del ligamento deltoideo ${ }^{127}$ junto con una triple artrodesis permite el tratamiento quirúrgico con conservación de la articulación tibiotalar.

En el estadio IV-A, los ligamentos periastragalinos incompetentes pueden no ser capaces de soportar el aumento de la carga mecánica después de la fusión tibiotalar. La persistente inclinación del valgo después de la fusión puede promover este proceso desfavorable. Por lo tanto, la fusión aislada debe realizarse con precaución para el tratamiento de los aquellos tobillos desviados en valgo. Si esto se considera, es recomendable que se intente la fusión en posiciones neutras o incluso ligeramente en varo. ${ }^{128}$

En el estadio IV-B, la deformidad es rígida y esencialmente irreductible. La falla del ligamento deltoideo permite que el astrágalo se luxe en valgo dentro de la mortaja articular.

La cirugía en estos casos debe ser la artrodesis tibioastragalina aislada o triple artrodesis que vendrá determinada por la propia deformidad. ${ }^{129}$

En caso de indicar una triple artrodesis, incluso con estabilización rígida del astrágalo en la mortaja, la inestabilidad periastragalina y el valgo pueden persistir, permitiendo la subluxación de calcáneo y escafoides alrededor del astrágalo, lo que produce una desestabilización progresiva del complejo del retropié.

Los pacientes que presenten deformidad con tobillo valgo rígido o una deformidad flexible pero acompañada de artrosis tibioastragalina avanzada (estadio IV-B) requieren tratamiento quirúrgico mediante artrodesis tibiotalar. $\mathrm{Pu}-$ blicaciones recientes de Smith y Bluman refieren que los resultados más fiables para el estadio IV-B, se obtienen mediante artrodesis tibio astrágalo calcánea con clavo retrogrado (Figura 11). ${ }^{122}$

La fusión tibio astrágalo calcánea o panastrágalodesis ha sido el estándar de oro para el tratamiento del estadio IV-B. Sin embargo, en algunos de estos pacientes la deformidad tibioastragalina es corregible sin fusionar la articulación, lo que permite implantar una prótesis total de tobillo posteriormente (Walling AOFAS 2004).

En ocasiones, con estabilización rígida del astrágalo en la mortaja del tobillo, la inestabilidad periastragalina puede 
persistir y permitir la subluxación de calcáneo y escafoides alrededor del astrágalo, lo que puede evolucionar a una desestabilización progresiva del complejo del retropié.
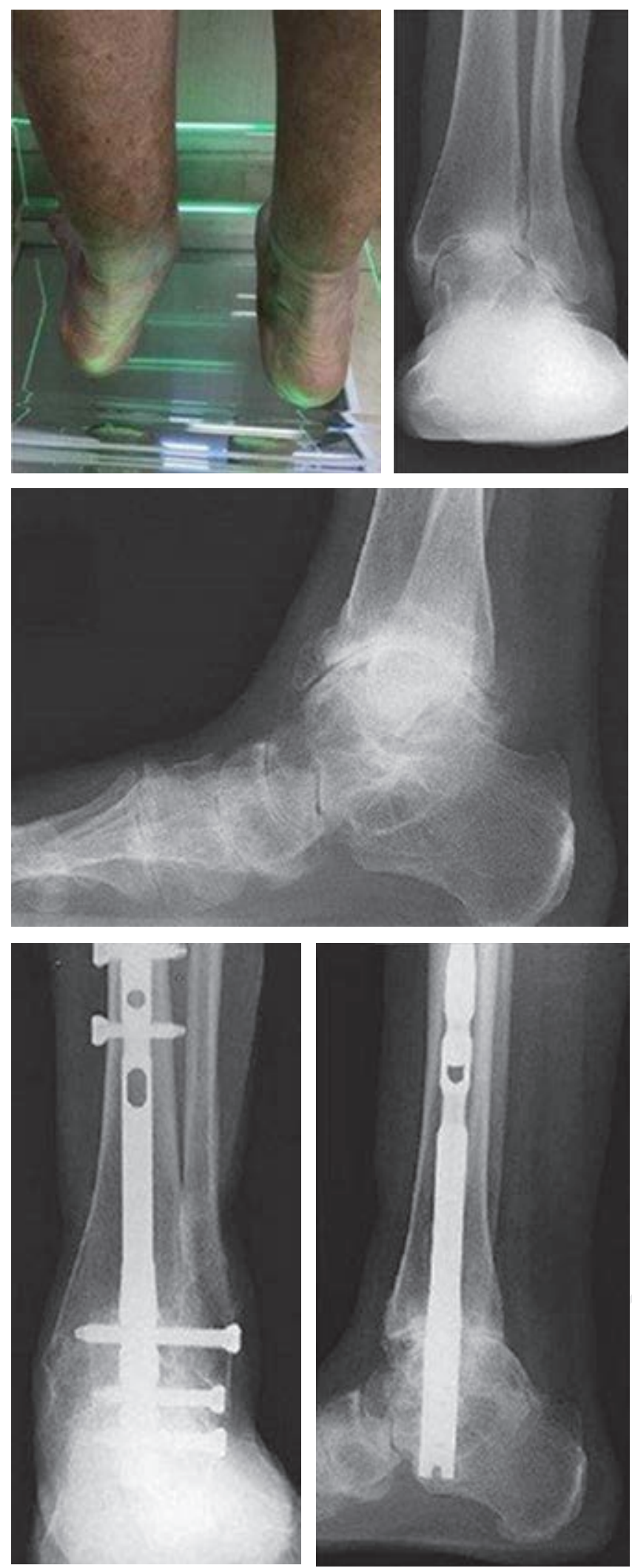

Figura 11: Valgo inestable, artrodesis tibio astrágalo calcánea.

\section{Comentarios finales}

\section{Disfunción del tibial posterior. ¿Causa o efecto recíproco?}

Tradicionalmente la insuficiencia del tibial posterior se considera la causa más común del pie plano del adulto. Nosotros como cirujanos del pie actualmente cuestionamos la actual clasificación y los errores fundamentales que presenta; ha sido utilizada desde hace más de 30 años. ${ }^{130}$

Johnson y Storm en 1989 propusieron una secuencia de estadios con falla progresiva del tibial posterior hasta su ruptura ocasionando una secuencia de cambios estructurales en el pie que ocasionaban una deformidad fija en plano valgo como consecuencia final. ${ }^{2} \mathrm{Su}$ sistema de clasificación tanto anatómico como clínico ha sido actualmente aceptado como el estándar en el diagnóstico y tratamiento; pensamos que presenta defectos para tratar de dilucidar la verdadera patogénesis de la enfermedad. ${ }^{2,42,63,131}$

Esta deformidad se basaba en la falla funcional del tendón tibial posterior, se suponía que ocurría por dos razones. En primer lugar, el tendón presenta una sinovitis espontánea y la tracción que ejercía el tendón no era efectiva para mantener el arco longitudinal medial. El tibial posterior es el soporte dinámico primario para el arco longitudinal interno y su función ya ha sido expuesta anteriormente en el apartado de morfología funcional. Durante la locomoción, el tendón se mueve a través de una distancia de 1 a $1.5 \mathrm{~cm}$ y pequeños aumentos en su longitud, debido a la sinovitis conduce a un colapso significativo en su función. Se cree que esto hace que sea ineficaz para elevar el arco longitudinal medial del pie que conduce al colapso del arco medial y ocasiona un pie plano. ${ }^{63}$ La fascia plantar, los ligamentos plantares y el complejo del ligamento en hamaca deben fallar antes del colapso del arco. Es importante recordar que la fascia plantar tiene tres veces más fuerza para mantener el arco medial en comparación con el tibial posterior.

La deformidad final tiene varios componentes que incluyen plano, valgo del retropié y abducción del antepié. Los cambios articulares fijos y la degeneración son un fenómeno que ocurre en etapas avanzadas., ${ }^{2,42,63}$

Desafiando la teoría existente dentro de la comunidad ortopédica, los términos pie plano adquirido del adulto e insuficiencia del tibial posterior y disfunción del tibial posterior se usan indistintamente reforzando inapropiadamente nuestra creencia de que el pie plano-valgo sólo existe como consecuencia de la insuficiencia del tibial posterior. El papel del ligamento en hamaca y su contribución a sostener el arco longitudinal ha sido poco valorado y a menudo ignorado como parte de la planificación del tratamiento. . $^{33,34}$

En 2001, Yeap (citado anteriormente) en un artículo clave que describe los resultados de realizar transferencias al tendón del tibial posterior, refiere en una serie de 12 pacientes, que ninguno desarrolló la deformidad en plano valgo que se podía haber esperado. ${ }^{132}$ El seguimiento fue de 90 meses (rango de 24 a 300), la escala del estudio fue mo- 
desta y el rango de edad de los pacientes significativamente diferente de la población de mayor edad. Al no encontrar colapso del arco longitudinal interno nos lleva a cuestionar la etiología tradicional.

Un estudio similar realizado por Mizel ${ }^{133}$ en el que analizó a 10 pacientes con parálisis traumática completa del nervio peroneo común, sin antecedentes de cirugía de pie o tobillo o trauma distal a la rodilla, que se habían sometido a transferencia del tendón tibial posterior al centro del pie. Seis tenían una transferencia del tendón al centro del pie y cuatro tuvieron un procedimiento de tenodesis de la mitad del tendón tibial posterior al tendón peroneo largo.

A 74.9 meses de seguimiento (rango 18-351 meses) todos los pies de los pacientes fueron evaluados para valorar la fuerza muscular, el arco longitudinal y el movimiento en el tobillo, articulación subastragalina y articulación de Chopart. En ningún caso hubo valgo del retropié asociado con la falta del tibial posterior. Sus conclusiones fueron: parece que la disfunción asociada con deficiencia en el tendón tibial posterior no se manifestará si la función del peroneo corto está ausente.

Pasapula y colaboradores ${ }^{130}$ quienes en 10 casos de transferencia del tibial posterior para pie cavo y pie péndulo utilizaron la transferencia del tibial posterior, no pudieron comprobar en un solo caso la presentación del pie plano durante un período de seguimiento de dos a ocho años. A pesar del uso de la traslación lateral del pie como guía para comprobar la lesión del ligamento en hamaca, con disminución de la tensión del ligamento, no hubo aumento demostrable en la traslación lateral en nueve pies y sin presencia clínica de plano valgo en ningún pie. Estos estudios cuestionan el papel esencial del tibial posterior y demuestran claramente que su ausencia no necesariamente conduce al pie plano valgo. Ha surgido evidencia creciente que establece la patología primaria, de hecho, esta enfermedad se debe completamente al fracaso de las restricciones estáticas y lo más importante, la falla del ligamento en hamaca. ${ }^{34,133,134}$

Deland ${ }^{135}$ en un estudio en cadáver demostró que la deformidad en plano valgo se produjo seccionando sistemáticamente los ligamentos plantares y que la deformidad se corrigió reconstruyendo el ligamento en hamaca, usando un injerto osteotendinoso.

Saxby demostró casos de falla del ligamento en hamaca sin sinovitis del tendón tibial posterior en un pie plano valgo. Orr $^{26}$ reportó seis pacientes, todas mujeres, que presentaron ruptura aislada del ligamento en hamaca y aparentemente con un tibial posterior normal, todos los pacientes presentaban una posición normal del retropié después de la cirugía de reparación del ligamento en hamaca y/o artrodesis.

Jennings y colaboradores en cinco muestras de cadáveres utilizaron un sistema cinemático tridimensional y un marco personalizado en el modelo in vitro cuantificando la rotación del astrágalo, escafoides y el calcáneo antes y después de seccionar el complejo del ligamento en hamaca mientras ponían en tensión el tendón del tibial posterior. ${ }^{46}$ Después de seccionar el complejo de los ligamentos en hamaca se mostraron cambios en la rotación del astrágalo, escafoides y calcáneo. Es importante destacar que demostraron que la sección del complejo del ligamento en hamaca por sí solo ocasionó inestabilidad en el pie, el tendón tibial posterior intacto no pudo compensar la posición del pie y llegaron a la conclusión de que el ligamento en hamaca era el principal estabilizador del arco longitudinal interno durante la bipedestación. Concluyeron que debe evaluarse la integridad del complejo del ligamento en hamaca y si está indicado, debe repararse en la cirugía de reconstrucción del pie plano.

Con respecto al sistema de clasificación de Johnson y Strom señalamos que puede presentar errores. Nunca ha habido un estudio tanto anatómico como cadavérico que demuestre la progresión de un escenario al otro. Sin embargo, estos supuestos se han convertido en parte de nuestro pensamiento tradicional. La etiología se centra en el tibial posterior erróneamente y, por lo tanto, evita el enfoque de otras estructuras que fallan cuando se presenta el pie plano del adulto.

Johnson y Strom parecen vincular conclusiones sobre el estado del pie por fallo del tendón tibial posterior. En cada etapa de la deformidad hay un cambio físico en la forma del pie; sin embargo, las deformidades que caracterizan al cuadro clínico sobre el estado del tendón pueden no ocurrir siempre. Comprobar el alargamiento del tendón no es posible y puede ser una suposición falsa de larga data.

El artículo de Johnson también comienza con la suposición de que el pie inicia en una postura neutra que luego pasa a plano valgo, pero varios autores han descrito una asociación de la disfunción del tibial posterior con un pie plano preexistente. ${ }^{37}$ La clasificación de Johnson no toma en cuenta el grado de un plano valgo preexistente. ${ }^{136,137}$ Jahss observó un pie plano preexistente en $100 \%$ de los pacientes de su propia serie. El artículo parece no contener datos reales y ninguna publicación posterior examinó la confiabilidad y reproducibilidad del sistema de Johnson o el por qué influye en la toma de decisiones clínicas.

El ultrasonido y la resonancia magnética se utilizan cada vez más para diagnosticar la disfunción del tibial posterior; sin embargo, el ultrasonido depende más del operador. No hay estudios que hayan podido vincular los hallazgos ecográficos del tendón con la evaluación del pronóstico.

El pie puede ser plano valgo, pero no presentar sinovitis alrededor del tendón. Tampoco es posible establecer si el tendón está elongado y ningún estudio en los Estados Unidos ha sido capaz de probar esa teoría.

El sistema de clasificación finalmente también simplifica la enfermedad en estadio 2 que puede resumirse con la pérdida de cuatro componentes:

1. Inestabilidad tarso-metatarsal.

2. Deformidad fija en supinación.

3. Sistema talo-aquíleo plantar corto.

4. Falla del ligamento en hamaca. 
Estos componentes deben ser identificados y evaluados de manera individual y clínica. También se ha descrito recientemente una prueba clínica para la evaluación del complejo del ligamento en hamaca.

Según la nueva teoría de la etiología del pie plano valgo Pasapula ${ }^{34}$ indica que «el ligamento en hamaca es el problema más importante en el pie plano adquirido del adulto», la sinovitis del tibial posterior se produce de manera secundaria. Es muy probable que la estructura que falla primero sea este complejo ligamentario. Los factores biomecánicos que pueden influir (deficiencia en el estado del colágeno, obesidad y pie plano valgo preexistente).

El fallo primero conduce a sobrecarga mecánica del tibial posterior que se refleja como sinovitis y disfunción. Esto es similar a la sobrecarga y disfunción de los peroneos en el pie cavo donde el tendón peroneo lateral corto presenta sinovitis debido a sobrecarga biomecánica. Por lo tanto: «en el estadio 2 del pie plano, según lo descrito por Johnson, no puede ocurrir sin la atenuación o ruptura del ligamento en hamaca». Este evento sería seguido por la falla de los otros ligamentos y causar una sinovitis biomecánica secundaria del tibial posterior. ${ }^{34,134}$

Esta teoría es reafirmada por Singh, quien mostró que en los pacientes sin función del tibial posterior, la transferencia de tendones para pies neurológicos no necesariamente desarrolla un pie plano, incluso en presencia de la función del peroneo corto, ${ }^{132}$ la enfermedad en estadio I en que se produzca sinovitis espontánea es poco probable. La incidencia general de plano valgo en los pies en pacientes con sinovitis primaria extensa se pueden evaluar en la población reumática.

Los pacientes con artritis reumatoide tienen sólo 11\% de incidencia de plano valgo en algunos estudios. Esto sugiere que, a pesar de la inflamación en el tendón y los ligamentos, el pie no puede desarrollar siempre un plano valgo. Es más probable que el tendón presente sinovitis como resultado de un entorno biomecánico anormal. ${ }^{37}$

Dyal ${ }^{138}$ demostró que $70 \%$ de los pacientes con síntomas unilaterales, el tendón tibial posterior tenía un pie plano contralateral, lo que implica que el pie sintomático probablemente era plano desde un inicio.

Este perfil biomecánico permite más fácilmente una falla del ligamento en hamaca y es la tensión del tibial posterior la que permite que el pie se vaya de un estado de plano valgo estable a inestable, demostrado por estudios mediante resonancia magnética.

Según este autor, los pies planos muestran anormalidades en el ligamento en hamaca así como del tendón del tibial posterior en casi todos los pies. La mayoría mostró además anormalidades en los ligamentos deltoideos superficiales, interóseos y astrágalo calcáneos. ${ }^{138}$ La imagen radiográfica inicial no puede diferenciar entre el pie plano valgo estable y el pie plano valgo inestable doloroso. Creemos que en el pie plano valgo no doloroso el ligamento en hamaca no ha fallado y no hay inestabilidad tarso metatarsiana y el pie está estáticamente restringido.
Se propondrá una clasificación alternativa. La clasificación ha sido revisada para centrarse en el ligamento en hamaca. Se cree que si se produce una tendinopatía debido a un pie plano inestable, esto sugeriría que debe haber una etapa pretendinopatía donde se rompe el ligamento en hamaca y el tendón aún no se vuelve hiperactivo o con sinovitis. La falla del ligamento en hamaca a menudo puede ser difícil de diagnosticar, ${ }^{136}$ puede ser aislada y comprobarse con la prueba de single rise. Pasapula cree que en la falla temprana se mide el eje astrágalo escafoideo para ejemplificar la tensión que se desarrolla en el ligamento en hamaca.

El ligamento es en gran medida una estructura medial que al fracasar da como resultado una deformidad del pie mucho antes del desarrollo del plano valgo.

Pasapula describió también este estadio como enfermedad en etapa $\mathbf{0}$ donde el ligamento en hamaca comienza a fallar, como lo indica la traslación lateral excesiva del pie que aún no ha progresado a plano valgo y el tibial posterior no presenta sinovitis. ${ }^{33,34}$

En el estadio I y II de la enfermedad existe atenuación o ruptura del ligamento en hamaca con sinovitis secundaria alrededor del tendón tibial posterior como fue descrito por Johnson y Strom. Pasapula propone una «reclasificación» de la clasificación original de Johnson y Strom de 1989 con más enfoque en el ligamento en hamaca. Su objetivo era reconocer la falla del ligamento en hamaca en el pie plano asintomático, este nuevo sistema de clasificación pone como estadio asintomático el estadio $0 .{ }^{33,34}$ La enfermedad en estadio II es una mezcla de problemas complejos con enfermedad progresiva, falla de la columna medial que comienza con cuatro problemas asociados, los primeros tres son deformidades progresivas:

1. Fallo del ligamento en hamaca (identificado por la single rise test). La deformidad se produce entonces en la articulación astragaloescafoidea. Si ésta se produce en articulaciones más distales es indicio de la integridad del spring ligament (Viladot Voegeli A.).

2. Inestabilidad tarso-metatarsiana con dorsiflexión permanente del primer metatarsiano o una deformidad fija en supinación una vez que el retropié haya sido puesto nuevamente en neutro.

3. Acortamiento del complejo gastrosóleo primario o secundario (imposible de diferenciar).

4. Esta nueva perspectiva tiene implicaciones en el manejo del pie plano del adulto. Reconocer tempranamente la tensión que se desarrolla en el ligamento en hamaca nos lleva a una intervención más temprana y esta cirugía puede conducir a prevención de nuevas fallas y mayor inestabilidad de más estructuras en el pie.

El fracaso para abordar el ligamento en hamaca de manera efectiva en la intervención puede conducir a altas tasas de recurrencia, particularmente en grandes correcciones. Niki y colaboradores ${ }^{139}$ informaron sus resultados en 25 pacientes que se sometieron a una osteotomía de calcáneo con transfe- 
rencia del tendón del flexor largo y demostraron que sólo dos parámetros radiográficos habían mejorado. En esta serie los autores llegaron a la conclusión de que este procedimiento sólo tenía una efectividad limitada, excepto para realizar pequeñas correcciones. ${ }^{139}$ Más recientemente, en un trabajo realizado en cadáver para probar diferentes reconstrucciones, los modelos del ligamento en hamaca de Pasapula han demostrado que la reconstrucción del ligamento en hamaca se realiza con más éxito con un internal brace. Esto es muy superior a una reparación primaria, una reconstrucción únicamente con sutura. También demostró en el modelo biomecánico que cuando se aplica carga, una transferencia del flexor largo no mejora la translación lateral del pie. ${ }^{122}$

\section{Referencias}

1. Ananthakrisnan D, Ching R, Tencer A, Hansen ST Jr, Sangeorzan BJ. Subluxation of the talocalcaneal joint in adults who have symptomatic flatfoot. J Bone Joint Surg Am. 1999; 81(8): 1147-54.

2. Johnson KA, Strom DE. Tibialis posterior tendon dysfunction. Clin Orthop Relat Res. 1989; (239): 196-206.

3. Hicks JH. The foot as a support. Acta Anat (Basel). 1955;25(1): 34-45.

4. Mann RA. Biomechanics of the foot and ankle. In: Mann RA, Coughlin MJ (eds). Surgery of the foot and ankle. St Louis: Mosby; 1993. pp. 3-43.

5. Thordarson DB, Schmotzer H, Chon J, Peters J. Dynamic support of the human longitudinal arch. A biomechanical evaluation. Clin Orthop Relat Res. 1995; (316): 165-72.

6. Huang CK, Kitaoka HB, An KN, Chao EY. Biomechanical evaluation of longitudinal arch stability. Foot Ankle. 1993; 14(6): 353-7.

7. Deland JT, de Asla RJ, Sung IH, Ernberg LA, Potter HG. Posterior tibial tendon insufficiency: which ligaments are involved? Foot Ankle Int. 2005; 26(6): 427-35.

8. Davis WH, Sobel M, DiCarlo EF, Torzilli PA, Deng X, Geppert $\mathrm{MJ}$, et al. Gross, histological, and microvascular anatomy and biomechanical testing of the spring ligament complex. Foot Ankle Int. 1996; 17(2): 95-102.

9. Campbell KJ, Michalski MP, Wilson KJ, Goldsmith MT, Wijdicks CA, LaPrade RF, et al. The ligament anatomy of the deltoid complex of the ankle: a qualitative and quantitative anatomical study. $J$ Bone Joint Surg Am. 2014; 96(8): e62.

10. Kobezda T. The role of the foot in the mechanism of shock absorption. Biomechanica Hungarica. 2009; 2: 31-8.

11. Jones RL. The human foot. An experimental study of its mechanics, and the role of its muscle and ligaments in the support of the arch. Am J Anat. 1941; 68: 1-39.

12. Hicks JH. The mechanics of the foot. IV. The action of muscles on the foot in standing. Acta Anat (Basel). 1956; 27(3): 180-92.

13. Houtz SJ, Fischer FJ. Function of leg muscles acting on foot as modified by body movements. J Appl Physiol. 1961; 16: 597-605.

14. Imhauser CW, Siegler S, Abidi NA, Frankel DZ. The effect of posterior tibialis tendon dysfunction on the plantar pressure characteristics and the kinematics of the arch and the hindfoot. Clin Biomech (Bristol, Avon). 2004; 19(2): 161-9.

15. Basmajian JV, Stecko G. The role of muscles in arch support of the foot. J Bone Joint Surg Am. 1963; 45: 1184-90.

16. Núñez-Samper M. Análisis anatomo funcional y estadístico de los sistemas estadísticos de la bóveda plantar del pie plano. Tesis doctoral. Madrid: Universidad Complutense; 1980.

17. Mann R, Inman VT. Phasic activity of intrinsic muscles of the foot. $J$ Bone Joint Surg Am. 1964; 46: 469-81.

18. Núñez-Samper M, Llanos Alcázar LF, Gómez Pellico L. Importancia de la musculatura plantar como soporte activo de los arcos del pie plano. Rev Ortop Traum. 1986; 30(5): 495-506.

19. Suzuki N. An electromyographic study of the role of muscles in arch support of the normal and flat foot. Nagoya Med J. 1972; 17(3): 57-79.
20. Sulowska I, Oleksy L, Mika A, Bylina D, Soltan J. The influence of plantar short foot muscle exercises on foot posture and fundamental movement patterns in long-distance runners, a non-randomized, nonblinded clinical trial. PLoS One. 2016; 11(6): e0157917.

21. Kitaoka HB, Luo ZP, An KN. Effect of the posterior tibial tendon on the arch of the foot during simulated weightbearing: biomechanical analysis. Foot Ankle Int. 1997; 18(1): 43-6.

22. Dullaert K, Hagen JE, Simons P, Gras F, Gueorguiev B, Richards RG, et al. Influence of tibialis posterior muscle activation on foot anatomy under axial loading: A biomechanical CT human cadaveric study. Foot Ankle Surg. 2017; 23(4): 250-4.

23. Borton DC, Saxby TS. Tear of the plantar calcaneonavicular (spring) ligament causing flatfoot. A case report. J Bone Joint Surg Br. 1997; 79(4): 641-3.

24. Kadakia AR, Kelikian AS, Barbosa M, Patel MS. Did failure occur because of medial column instability that was not recognized, or did it develop after surgery? Foot Ankle Clin. 2017; 22(3): 545-62.

25. Gazdag AR, Cracchiolo A 3rd. Rupture of the posterior tibial tendon. Evaluation of injury of the spring ligament and clinical assessment of tendon transfer and ligament repair. J Bone Joint Surg Am. 1997; 79(5): 675-81.

26. Orr JD, Nunley JA 2nd. Isolated spring ligament failure as a cause of adult-acquired flatfoot deformity. Foot Ankle Int. 2013; 34(6): 818-23.

27. Larrainzar-Garijo R, Cifuentes de la Portilla C, Gutiérrez-Narvarte B, Díez-Nicolás E, Bayod J. Effect of the calcaneal medializing osteotomy on soft tissues supporting the plantar arch: A computational study. Rev Esp Cir Ortop Traumatol (Engl Ed). 2019; 63(2): 155-63.

28. Greisberg J, Assal M, Hansen ST Jr, Sangeorzan BJ. Isolated medial column stabilization improves alignment in adult-acquired flatfoot. Clin Orthop Relat Res. 2005; (435): 197-202.

29. Yeap JS, Singh D, Birch R. Tibialis posterior tendon dysfunction: a primary or secondary problem? Foot Ankle Int. 2001; 22(1): 51-5.

30. Subhas N, Sundaram M. Isolated spring ligament tear demonstrated on magnetic resonance imaging. Orthopedics. 2007; 30(1): 70-2.

31. Tryfonidis M, Jackson W, Mansour R, Cooke PH, Teh J, Ostlere S, et al. Acquired adult flat foot due to isolated plantar calcaneonavicular (spring) ligament insufficiency with a normal tibialis posterior tendon. Foot Ankle Surg. 2008; 14(2): 89-95.

32. Williams G, Widnall J, Evans P, Platt S. Could failure of the spring ligament complex be the driving force behind the development of the adult flatfoot deformity? J Foot Ankle Surg. 2014; 53(2): 152-5.

33. Pasapula C, Devany A, Fischer NC, Wijdicks CA, Hübner T, Reifenscneider $\mathrm{F}$, et al. The resistance to failure of spring ligament reconstruction. Foot (Edinb). 2017; 33: 29-34.

34. Pasapula C, Devany A, Magan A, Memarzadeh A, Pasters V, Shariff S. Neutral heel lateral push test: The first clinical examination of spring ligament integrity. Foot (Edinb). 2015; 25(2): 69-74.

35. Pisani G. About the pathogenesis of the so-called adult acquired pes planus. Foot Ankle Surg. 2010; 16(1): 1-2.

36. Brodell JD Jr, MacDonald A, Perkins JA, Deland JT, Oh I. DeltoidSpring ligament reconstruction in adult acquired flatfoot deformity with medial peritalar instability. Foot Ankle Int. 2019; 40(7): 753-61.

37. Myerson M, Solomon G, Shereff M. Posterior tibial tendon dysfunction: its association with seronegative inflammatory disease. Foot Ankle. 1989; 9(5): 219-25.

38. Funk DA, Cass JR, Johnson KA. Acquired adult flat foot secondary to posterior tibial-tendon pathology. J Bone Joint Surg Am. 1986; 68(1): 95-102.

39. Frey C, Shereff M, Greenidge N. Vascularity of the posterior tibial tendon. J Bone Joint Surg Am. 1990; 72(6): 884-8.

40. Prado MP, de Carvalho AE Jr, Rodrigues CJ, Fernandes TD, Mendes AA, Salomao O. Vascular density of the posterior tibial tendon: a cadaver study. Foot Ankle Int. 2006; 27(8): 628-31.

41. Núñez Samper M, Llanos Alcázar LF, Martín Guinea J, Gómez Pellico L. Análisis funcional y estadístico de los sistemas estáticos de la bóveda plantar. Chirurgia del Piede. 1984; 8(3): 147-50.

42. Bluman EM, Title CI, Myerson MS. Posterior tibial tendon rupture: a refined classification system. Foot Ankle Clin. 2007; 12(2): 233-49. 
43. Raikin SM, Winters BS, Daniel JN. The RAM classification: a novel, systematic approach to the adult-acquired flatfoot. Foot Ankle Clin. 2012; 17(2): 169-81.

44. Viladot R, Viladot A Jr, Álvarez F. Pie plano laxo infantil. En: Kellam JF. Actualizaciones en cirugía ortopédica y traumatología. 2a ed. Barcelona: Masson; 2001. pp. 229-37.

45. Herráiz Hidalgo L, Carrascoso Arranz J, Recio Rodríguez M, Jiménez de la Peña M, Cano Alonso R, Álvarez Moreno E, et al. Disfunción del tendón tibial posterior: ¿qué otras estructuras están implicadas en el desarrollo del pie plano adquirido del adulto? Radiologia. 2014; 56(3): 247-56.

46. Jennings MM, Christensen JC. The effects of sectioning the spring ligament on rearfoot stability and posterior tibial tendon efficiency. $J$ Foot Ankle Surg. 2008; 47(3): 219-24.

47. Lee MS, Maker JM. Revision of failed flatfoot surgery. Clin Podiatr Med Surg. 2009; 26(1): 47-58.

48. Mosier-LaClair S, Pomeroy G, Manoli A 2nd. Operative treatment of the difficult stage 2 adult acquired flatfoot deformity. Foot Ankle Clin. 2001; 6(1): 95-119.

49. Maker JM, Cottom JM. Surgical management of stage 2 adult acquired flatfoot. Clin Podiatr Med Surg [Internet]. 2014; 31(3): 3819. Available in: http://dx.doi.org/10.1016/j.cpm.2014.03.002

50. Hibbs RA. Muscle bound feet. NY Med J. 1914; 17(C): 797-9.

51. Barouk P, Barouk LS. Clinical diagnosis of gastrocnemius tightness. Foot Ankle Clin [Internet]. 2014; 19(4): 659-67. Available in: http:// dx.doi.org/10.1016/j.fcl.2014.08.004

52. Viladot R, Pons M, Alvarez F, Omaña J. Subtalar arthroereisis for posterior tibial tendon dysfunction: a preliminary report. Foot Ankle Int. 2003; 24(8): 600-6.

53. Wake J, Martin K. Posterior tibial tendon endoscopic debridement for stage I and II posterior tibial tendon dysfunction. Arthrosc Tech. 2017; 6(5): e2019-22.

54. Walley KC, Greene G, Hallam J, Juliano PJ, Aynardi MC. Short- to mid-term outcomes following the use of an arthroereisis implant as an adjunct for correction of flexible, acquired flatfoot deformity in adults. Foot Ankle Spec. 2018; 12: 122-30.

55. Charwat-Pessler CG, Hofstaetter SG, Jakubek DE, Trieb K. Interference screw for fixation of FDL transfer in the treatment of adult acquired flat foot deformity stage II. Arch Orthop Trauma Surg. 2015; 135(10): 1369-78.

56. Conti MS, Jones MT, Savenkov O, Deland JT, Ellis SJ. Outcomes of reconstruction of the stage II adult-acquired flatfoot deformity in older patients. Foot Ankle Int. 2018; 39(9): 1019-27.

57. Moseir-LaClair S, Pomeroy G, Manoli A 2nd. Intermediate follow-up on the double osteotomy and tendon transfer procedure for stage II posterior tibial tendon insufficiency. Foot Ankle Int. 2001; 22(4): 283-91.

58. Weil LS Jr, Benton-Weil W, Borrelli AH, Weil LS Sr. Outcomes for surgical correction for stages 2 and 3 tibialis posterior dysfunction. $J$ Foot Ankle Surg. 1998; 37(6): 467-71; discussion 550.

59. Sangeorzan BJ, Mosca V, Hansen ST Jr. Effect of calcaneal lengthening on relationships among the hindfoot, midfoot, and forefoot. Foot Ankle. 1993; 14(3): 136-41.

60. Grice DS. An extra-articular arthrodesis of the subastragalar joint for correction of paralytic flat feet in children. J Bone Joint Surg Am. 1952; 34A(4): 927-40.

61. Viladot A. Surgical treatment of the child's flatfoot. Clin Orthop Relat Res. 1992; (283): 34-8.

62. Maxwell JR, Carro A, Sun C. Use of the Maxwell-Brancheau arthroereisis implant for the correction of posterior tibial tendon dysfunction. Clin Podiatr Med Surg. 1999; 16(3): 479-89.

63. Myerson MS. Adult acquired flatfoot deformity: treatment of dysfunction of the posterior tibial tendon. Instr Course Lect. 1997; 46: 393-405.

64. Barouk LS. Gastrocnemius proximal release. In: Barouk LS. Forefoot reconstruction. Paris: Springer; 2003.

65. Ruiz Nasarre A, Álvarez Goenaga F, Viladot Pericé R, Fernández de Retana P. Doble artrodesis del tarso por vía medial: primeros dieciséis casos. Rev Pie Tobillo. 2013; 27(2): 92-7.

66. Viladot Voegeli A, Fontecilla Cornejo N, Serrá Sandoval JA, Alvarez Goenaga F, Viladot Pericé R. Results of subtalar arthroereisis for posterior tibial tendon dysfunction stage IIA1. Based on 35 patients. Foot Ankle Surg. 2018; 24(1): 28-33.

67. Pinney SJ, Lin SS. Current concept review: acquired adult flatfoot deformity. Foot Ankle Int. 2006; 27(1): 66-75.

68. Kitaoka HB, Luo ZP, An KN. Reconstruction operations for acquired flatfoot: biomechanical evaluation. Foot Ankle Int. 1998; 19(4): 203-7.

69. Haddad SL, Myerson MS, Younger A, Anderson RB, Davis WH, Manoli A 2nd. Symposium: adult acquired flatfoot deformity. Foot Ankle Int. 2011; 32(1): 95-111.

70. Silver CM, Simon SD, Spindell E, Litchman HM, Scala M. Calcaneal osteotomy for valgus and varus deformities of the foot in cerebral palsy. A preliminary report on twenty-seven operations. J Bone Joint Surg Am. 1967; 49(2): 232-46.

71. Dwyer FC. Osteotomy of the calcaneum for pes cavus. $J$ Bone Joint Surg Br. 1959; 41-B(1): 80-6.

72. Koutsogiannis E. Treatment of mobile flat foot by displacement osteotomy of the calcaneus. J Bone Joint Surg Br. 1971; 53(1): 96100.

73. Mann RA, Thompson FM. Rupture of the posterior tibial tendon causing flat foot. Surgical treatment. J Bone Joint Surg Am. 1985; 67(4): 556-61.

74. Myerson MS, Badekas A, Schon LC. Treatment of stage II posterior tibial tendon deficiency with flexor digitorum longus tendon transfer and calcaneal osteotomy. Foot Ankle Int. 2004; 25(7): 445-50.

75. Pomeroy GC, Manoli A 2nd. A new operative approach for flatfoot secondary to posterior tibial tendon insufficiency: a preliminary report. Foot Ankle Int. 1997; 18(4): 206-12.

76. Fayazi AH, Nguyen HV, Juliano PJ. Intermediate term follow-up of calcaneal osteotomy and flexor digitorum longus transfer for treatment of posterior tibial tendon dysfunction. Foot Ankle Int. 2002; 23(12): 1107-11.

77. Wacker JT, Hennessy MS, Saxby TS. Calcaneal osteotomy and transfer of the tendon of flexor digitorum longus for stage-II dysfunction of tibialis posterior. Three- to five-year results. $J$ Bone Joint Surg Br. 2002; 84(1): 54-8.

78. Guyton GP, Jeng C, Krieger LE, Mann RA. Flexor digitorum longus transfer and medial displacement calcaneal osteotomy for posterior tibial tendon dysfunction: a middle-term clinical follow-up. Foot Ankle Int. 2001; 22(8): 627-32.

79. Sammarco GJ, Hockenbury RT. Treatment of stage II posterior tibial tendon dysfunction with flexor hallucis longus transfer and medial displacement calcaneal osteotomy. Foot Ankle Int. 2001; 22(4): 30512.

80. Hadfield M, Snyder J, Liacouras P, Owen J, Wayne J, Adelaar R. The effects of a medializing calcaneal osteotomy with and without superior translation on Achilles tendon elongation and plantar foot pressures. Foot Ankle Int. 2005; 26(5): 365-70.

81. Matheis EA, Spratley EM, Hayes CW, Adelaar RS, Wayne JS. Plantar measurements to determine success of surgical correction of stage iib adult acquired flatfoot deformity. J Foot Ankle Surg. 2014; 53(5): 562-6.

82. Arangio GA, Salathe EP. A biomechanical analysis of posterior tibial tendon dysfunction, medial displacement calcaneal osteotomy and flexor digitorum longus transfer in adult acquired flat foot. Clin Biomech (Bristol, Avon). 2009; 24(4): 385-90.

83. Den Hartog BD. Flexor digitorum longus transfer with medial displacement calcaneal osteotomy. Biomechanical rationale. Foot Ankle Clin. 2001; 6(1): 67-76.

84. Brodsky JW. Preliminary gait analysis results after posterior tibial tendon reconstruction: a prospective study. Foot Ankle Int. 2004; 25(2): 96-100.

85. Horton GA, Myerson MS, Parks BG, Park YW. Effect of calcaneal osteotomy and lateral column lengthening on the plantar fascia: a biomechanical investigation. Foot Ankle Int. 1998; 19(6): 370-3.

86. Bolt PM, Coy S, Toolan BC. A comparison of lateral column lengthening and medial translational osteotomy of the calcaneus for the reconstruction of adult acquired flatfoot. Foot Ankle Int. 2007; 28(11): 1115-23. 
87. Doty JF, Alvarez RG, Asbury BS, Rudd JN, Baxter WB. Arteriovenous fistula and pseudoaneurysm of the posterior tibial artery after calcaneal slide osteotomy: a case report. Foot Ankle Int. 2010; 31(4): 329-32.

88. Krause FG, Pohl MJ, Penner MJ, Younger AS. Tibial nerve palsy associated with lateralizing calcaneal osteotomy: case reviews and technical tip. Foot Ankle Int. 2009; 30(3): 258-61.

89. Ptaszek AJ, Aminian A, Schneider JR, Milos S. Lateral plantar artery pseudoaneurysm after calcaneal osteotomy: a case report. Foot Ankle Int. 2006; 27(2): 141-3.

90. Saxena A, Patel R. Medial displacement calcaneal osteotomy: a comparison of screw versus locking plate fixation. J Foot Ankle Surg. 2016; 55(6): 1164-8.

91. Kendal A, Ball T, Rogers M, Cooke P, Sharp R. Minimally invasive calcaneal osteotomy; a safe alternative to open calcaneal osteotomy with fewer complications. Orthop Proc [Internet]. 2018; 96-B(Supp 17).

92. Jowett CR, Rodda D, Amin A, Bradshaw A, Bedi HS. Minimally invasive calcaneal osteotomy: A cadaveric and clinical evaluation. Foot Ankle Surg. 2016; 22(4): 244-7.

93. Kheir E, Borse V, Sharpe J, Lavalette D, Farndon M. Medial displacement calcaneal osteotomy using minimally invasive technique. Foot Ankle Int. 2015; 36(3): 248-52.

94. Evans D. Relapsed club foot. J Bone Joint Surg Br. 1961; 43: 722-33.

95. Evans D. Calcaneo-valgus deformity. J Bone Joint Surg Br. 1975; 57(3): 270-8.

96. Mosca VS. Calcaneal lengthening for valgus deformity of the hindfoot. Results in children who had severe, symptomatic flatfoot and skewfoot. J Bone Joint Surg Am. 1995; 77(4): 500-12.

97. Dumontier TA, Falicov A, Mosca V, Sangeorzan B. Calcaneal lengthening: investigation of deformity correction in a cadaver flatfoot model. Foot Ankle Int. 2005; 26(2): 166-70.

98. Hix J, Kim C, Mendicino RW, Saltrick K, Catanzariti AR. Calcaneal osteotomies for the treatment of adult-acquired flatfoot. Clin Podiatr Med Surg. 2007; 24(4): 699-719.

99. Guha AR, Perera AM. Calcaneal osteotomy in the treatment of adult acquired flatfoot deformity. Foot Ankle Clin. 2012; 17(2): 247-58.

100. Hintermann B, Knupp M, Barg A. Peritalar instability. Foot Ankle Int. 2012; 33(5): 450-4.

101. Prissel MA, Roukis TS. Incidence of nonunion of the unfixated, isolated evans calcaneal osteotomy: a systematic review. J Foot Ankle Surg. 2012; 51(3): 323-5.

102. Haeseker GA, Mureau MA, Faber FW. Lateral column lengthening for acquired adult flatfoot deformity caused by posterior tibial tendon dysfunction stage II: a retrospective comparison of calcaneus osteotomy with calcaneocuboid distraction arthrodesis. $J$ Foot Ankle Surg. 2010; 49(4): 380-4.

103. Zwipp H, Rammelt S. Modified Evans osteotomy for the operative treatment of acquired pes planovalgus. Oper Orthop Traumatol. 2006; 18(2): 182-97.

104. Hintermann B, Valderrabano V, Kundert HP. Lengthening of the lateral column and reconstruction of the medial soft tissue for treatment of acquired flatfoot deformity associated with insufficiency of the posterior tibial tendon. Foot Ankle Int. 1999; 20(10): 622-9.

105. Dunn SP, Meyer J. Displacement of the anterior process of the calcaneus after Evans calcaneal osteotomy. J Foot Ankle Surg. 2011; 50(4): 402-6.

106. Frankel JP, Turf RM, Kuzmicki LM. Double calcaneal osteotomy in the treatment of posterior tibial tendon dysfunction. J Foot Ankle Surg. 1995; 34(3): 254-61.

107. Myerson MS. Adult acquired flatfoot deformity. J Bone Joint Surg. 1996; 78A: 780-92.

108. Kohls-Gatzoulis J, Angel JC, Singh D, Haddad F, Livingstone J, Berry G. Tibialis posterior dysfunction: a common and treatable cause of adult acquired flatfoot. BMJ. 2004; 329(7478): 1328-33.

109. Mann RA. Acquired flatfoot in adults. Clin Orthop Relat Res. 1983; (181): 46-51.

110. Mehta SK, Kellum RB, Robertson GH, Moore AR, Wingerter SA, Tarquinio TA. Radiographic correction of stage III posterior tibial tendon dysfunction with a modified triple arthrodesis. Foot Ankle Int. 2013; 34(10): 1355-63.
111. Bono JV, Jacobs RL. Triple arthrodesis through a single lateral approach: a cadaveric experiment. Foot Ankle. 1992; 13(7): 408-12.

112. Ryerson E. The classic: arthrodesing operations on the feet. Clin Orthop Relat Res. 1977; 122: 4-9.

113. Wapner KL. Triple arthrodesis in adults. J Am Acad Orthop Surg. 1998; 6(3): 188-96.

114. Smith RW, Shen W, Dewitt S, Reischl SF. Triple arthrodesis in adults with non-paralytic disease. A minimum ten-year follow-up study. $J$ Bone Joint Surg Am. 2004; 86(12): 2707-13.

115. Saltzman CL, Fehrle MJ, Cooper RR, Spencer EC, Ponseti IV. Triple arthrodesis: twenty-five and forty-four-year average follow-up of the same patients. J Bone Joint Surg Am. 1999; 81(10): 1391-402.

116. Pell RF 4th, Myerson MS, Schon LC. Clinical outcome after primary triple arthrodesis. J Bone Joint Surg Am. 2000; 82(1): 47-57.

117. Rosenfeld PF, Budgen SA, Saxby TS. Triple arthrodesis: is bone grafting necessary? The results in 100 consecutive cases. $J$ Bone Joint Surg Br. 2005; 87(2): 175-8.

118. Ahmad J, Pedowitz D. Management of the rigid arthritic flatfoot in adults: triple arthrodesis. Foot Ankle Clin. 2012; 17(2): 309-22. doi: 10.1016/j.fcl.2012.03.008.

119. Lambrinudi C. New operation of drop-foot. Br J Surg. 1927; 15: 193200.

120. Ryerson EW. Arthrodesing operations on the feet. $J$ Bone Joint Surg Am. 1923; 5: 453-71.

121. Wetmore RS, Drennan JC. Long-term results of triple arthrodesis in Charcot-Marie-Tooth disease. J Bone Joint Surg Am. 1989; 71(3): 417-22.

122. Bluman EM, Myerson MS. Stage IV posterior tibial tendon rupture. Foot Ankle Clin. 2007; 12(2): 341-62.

123. Smith JT, Bluman EM. Update on stage IV acquired adult flatfoot disorder: when the deltoid ligament becomes dysfunctional. Foot Ankle Clin. 2012; 17(2): 351-60.

124. Peterson KS, Hyer CF. Surgical decision making for stage IV adult acquired flatfoot disorder. Clin Podiatr Med Surg. 2014; 31(3): 445-54.

125. Conti MS, Ellis SJ, Chan JY, Do HT, Deland JT. Optimal position of the heel following reconstruction of the stage II adult-acquired flatfoot deformity. Foot Ankle Int. 2015; 36(8): 919-27.

126. Kunas GC, Probasco W, Haleem AM, Burket JC, Williamson ERC, Ellis SJ. Evaluation of peritalar subluxation in adult acquired flatfoot deformity using computed tomography and weightbearing multiplanar imaging. Foot Ankle Surg. 2018; 24(6): 495-500.

127. Jeng CL, Bluman EM, Myerson MS. Minimally invasive deltoid ligament reconstruction for stage IV flatfoot deformity. Foot Ankle Int. 2011; 32(1): 21-30.

128. Colin F, Zwicky L, Barg A, Hintermann B. Peritalar instability after tibiotalar fusion for valgus unstable ankle in stage IV adult acquired flatfoot deformity: case series. Foot Ankle Int. 2013; 34(12): 1677-82.

129. Parra PT. Manejo de la disfunción del tibial posterior. Ortho-tips. 2006; 2(4): 277-84.

130. Pasapula C, Cutts S. Modern theory of the development of adult acquired flat foot and an updated spring ligament classification system. Clin Res Foot Ankle. 2018; 5(3): 1000247.

131. Mueller TJ. Acquired flatfoot secondary to tibialis posterior dysfunction: biomechanical aspects. J Foot Surg. 1991; 30(1): 2-11.

132. Yeap JS, Birch R, Singh D. Long-term results of tibialis posterior tendon transfer for drop-foot. Int Orthop. 2001; 25(2): 114-8.

133. Mizel MS, Temple HT, Scranton PE Jr, Gellman RE, Hecht PJ, Horton GA, et al. Role of the peroneal tendons in the production of the deformed foot with posterior tibial tendon deficiency. Foot Ankle Int. 1999; 20(5): 285-9.

134. Myerson MS, Corrigan J, Thompson F, Schon LC. Tendon transfer combined with calcaneal osteotomy for treatment of posterior tibial tendon insufficiency: a radiological investigation. Foot Ankle Int. 1995; 16(11): 712-8.

135. Deland JT, Arnoczky SP, Thompson FM. Adult acquired flatfoot deformity at the talonavicular joint: reconstruction of the spring ligament in an in vitro model. Foot Ankle. 1992; 13(6): 327-32.

136. Jahss MH. Spontaneous rupture of the tibialis posterior tendon: clinical findings, tenographic studies, and a new technique of repair. Foot Ankle. 1982; 3(3): 158-66. 
137. Jahss MH. Tendon disorders of the foot and ankle. Philadelphia: W.B. Saunders; 1991. pp. 1461-513.

138. Dyal CM, Feder J, Deland JT, Thompson FM. Pes planus in patients with posterior tibial tendon insufficiency: asymptomatic versus symptomatic foot. Foot Ankle Int. 1997; 18(2): 85-8.

139. Niki H, Hirano T, Okada H, Beppu M. Outcome of medial displacement calcaneal osteotomy for correction of adult-acquired flatfoot. Foot Ankle Int. 2012; 33(11): 940-6.
Conflicto de intereses: Todos los autores no han percibido cantidad económica alguna y no tienen intereses comerciales con ninguna empresa o editorial por la redacción de este trabajo.

Todos los autores de este trabajo ceden el copyright a la $R e$ vista Acta Ortopédica Mexicana.

Madrid (España), Marzo de 2020. 